\title{
CAMA
}

Centre for Applied Macroeconomic Analysis

\section{Trend Inflation and Exchange Rate Dynamics: A New Keynesian Approach}

\section{CAMA Working Paper 74/2016 December 2016}

Takashi Kano

Graduate School of Economics, Hitotsubashi University

Tokyo Center for Economic Research and

Centre for Applied Macroeconomic Analysis, ANU

\section{Abstract}

The paper studies exchange rate implications of trend inflation within a two-country New Keynesian (NK) model under incomplete international financial markets. A NK Phillips curve generalized by trend inflation with a positive long-run mean implies an expectational difference equation of inflation with higher-order leads of expected inflation. The resulting two-country inflation differential is smoother, more persistent, and more insensitive to a real exchange rate. General equilibrium then yields (i) a persistent real exchange rate with an autoregressive root close to one, (ii) a hump-shaped impulse response of a real exchange rate with a half-life longer than four years, (iii) a volatile real exchange rate relative to cross-country inflation differential, (iv) an almost perfect comovement between real and nominal exchange rates and (v) a sharp rise in the volatility of a real exchange rate from a managed nominal exchange rate regime to a flexible one within an otherwise standard two-country NK model. Trend inflation, therefore, approaches empirical puzzles of exchange rates dynamics. 


\section{Keywords}

Real and Nominal Exchange Rates, Trend Inflation, New Keynesian Models

JEL Classification

E31, E52, F31, F41

Address for correspondence:

(E) cama.admin@anu.edu.au

ISSN 2206-0332

The Centre for Applied Macroeconomic Analysis in the Crawford School of Public Policy has been established to build strong links between professional macroeconomists. It provides a forum for quality macroeconomic research and discussion of policy issues between academia, government and the private sector.

The Crawford School of Public Policy is the Australian National University's public policy school, serving and influencing Australia, Asia and the Pacific through advanced policy research, graduate and executive education, and policy impact. 


\title{
Trend Inflation and Exchange Rate Dynamics: A New Keynesian Approach
}

\author{
Takashi Kano ${ }^{\dagger \ddagger}$ \\ Graduate School of Economics, Hitotsubashi University \\ Centre for Applied Macroeconomic Research, the Australian National University \\ Tokyo Center for Economic Research
}

Current Draft: December 15, 2016

\begin{abstract}
The paper studies exchange rate implications of trend inflation within a two-country New Keynesian (NK) model under incomplete international financial markets. A NK Phillips curve generalized by trend inflation with a positive long-run mean implies an expectational difference equation of inflation with higher-order leads of expected inflation. The resulting two-country inflation differential is smoother, more persistent, and more insensitive to a real exchange rate. General equilibrium then yields (i) a persistent real exchange rate with an autoregressive root close to one, (ii) a hump-shaped impulse response of a real exchange rate with a half-life longer than four years, (iii) a volatile real exchange rate relative to cross-country inflation differential, (iv) an almost perfect co-movement between real and nominal exchange rates. and (v) a sharp rise in the volatility of a real exchange rate from a managed nominal exchange rate regime to a flexible one within an otherwise standard two-country NK model. Trend inflation, therefore, approaches empirical puzzles of exchange rates dynamics.
\end{abstract}

Key Words: Real and Nominal Exchange Rates, Trend Inflation, New Keynesian Models

JEL Classification Number: E31, E52, F31, and F41

$\dagger$ Contacting Address: Graduate School of Economics, Hitotsubashi University, Naka 2-1, Kunitachi-city, Tokyo, 186-8601, Japan. Phone: +81-42-580-8283. Email: tkano@econ.hit-u.ac.jp.

$\ddagger$ I would like to thank Pablo Guerron-Quintana, Takushi Kurozumi, Moto Shintani, Youichi Ueno, and seminar participants at the 2nd Hitotsubashi Summer Institute (HSI 2016), the 10th International Conference on Computational and Financial Econometric (CFE 2016), and the Institute for Monetary and Economic Studies at the Bank of Japan for insightful discussions. I wish to thank a grant-in-aid for scientific research from the Japan Society for the Promotion of Science (number 24330060) and financial support from Hitotsubashi Institute for Advanced Study. I am solely responsible for any errors and misinterpretations of this paper. 


\section{Introduction}

Empirical reality of exchange rates keeps confounding researchers of international finance. Real exchange rates are very persistent as well as volatile. Near random-walk nominal exchange rates have no significant dependence on the current as well as the past information of macroeconomic fundamentals. Real and nominal exchange rates move together very closely. Nominal exchange rate regimes affect significantly real exchange rate dynamics. These stylized facts jointly defy theoretical challenges of canonical open-economy models with price stickiness. The literature of New Keynesian (NK) open-economy models is still far from satisfactory elucidation of the complicated life of exchange rates. ${ }^{1}$

In this paper, I scrutinize critical roles of trend inflation in exchange rate dynamics. ${ }^{2} \mathrm{My}$ investigation is based on an otherwise standard symmetric two-country NK model that is equipped with the Calvo-type time-dependent pricing behaviors of monopolistic competitive final goods firms conducting pricing-to-market strategies in foreign markets, Taylor-rule type monetary policies with interest rate smoothing, incomplete international financial markets, and permanent labor productivity shocks cointegrated across the two countries. I extend the standard NK model by allowing for trend inflation in two countries. As in Ireland (2007), the source of fluctuations in trend inflation is a time-varying inflation rate target that the central bank in each country sets in the Taylor rule. The inflation rate target follows a persistent but stationary stochastic process with a positive long-run mean. The persistent behaviors of trend inflation in the two countries are simply passed through to a slow-swing of the two-county inflation differential as observed in data. To my best knowledge, this paper is the first attempt to embed trend inflation into a two-country NK model explicitly and extract its implications on exchange rate dynamics.

Allowing for persistent trend inflation with a positive long-run mean within an open-economy NK models makes fundamentally richer equilibrium dynamics of real and nominal exchange rates. In this model, the real uncovered interest rate parity (RUIP) condition determines the real currency return, which then depends on the inflation differential as well as the output gap differential through the Taylor rules in the two countries. Trend inflation changes the dynamics of the inflation and output gap differentials essentially. First of all, a positive long-run mean of trend inflation substantially alters the shape of the log-linearized New Keynesian Phillips curve (NKPC) in each country, as discussed in Cogley and Sargent (2008) and Ascari and Sbordone (2014). In this NKPC generalized by trend inflation (hereafter, generalized NKPC: GNKPC) the current inflation rate follows a second-order expectational difference equation depending on rational expectations of the one and two period future inflation rates. As claimed by Cogley and Sbordone (2008), this dependence of the current inflation rate on higher-order expectations terms creates a persistent as well as less volatile movement of the inflation rate even without an ad hoc indexation of the current price setting behavior to the past inflation rates. Importantly, the GNKPCs of the two countries result in a looser relationship between the cross-county inflation differential and the real exchange rate than that in the standard model: the current inflation differential becomes less sensitive to a

\footnotetext{
${ }^{1}$ Burstein and Gopinath (2014) and Engel (2014) provide excellent surveys about the recent empirical findings related to international real and nominal relative prices.

${ }^{2}$ Ascari and Sbordone (2014) offer an excellent summary of the recent researches on trend inflation, especially focusing on the inflation dynamics in the United States.
} 
current development of the real exchange rate.

Second, a positive long-run trend inflation has a substantial impact on the cross-country differential in output gap. Through the market clearing conditions, the output gap differential is determined by the terms of trade (TOT) and the cross-country differential in the degree of price dispersions in the final goods markets. ${ }^{3}$ The terms of trade (TOT) dynamics become more persistent with a positive long-run mean of trend inflation: the TOT growth rate is characterized by a secondorder expectational difference equation with the expectations of the one and two period future TOT growth rates. Furthermore, the transition of the cross-country differential in price dispersion is backward-looking and its persistence relies on the long-run trend inflation positively. These novel roles of the long-run trend inflation in an open-economy NK environment yield more sluggish adjustments in aggregate hours worked, marginal costs, and the TOT. Therefore, the output gap differential between the two countries also becomes more persistent.

The trend inflation model of this paper convincingly explains both high persistence and large volatility of real exchange rates. Suppose for exposition that there is no response of the Taylor rule to the output gap. Recall that the inflation differential is less sensitive to the real exchange rate when the model is endowed with positive long-run trend inflation. In this situation, the RUIP condition solely characterizes the equilibrium real exchange rate as a near unit root process. The lesser the sensitivity of the inflation differential to the real exchange rate in the GNKPC, the closer to unity the AR root of the real exchange rate. Iterating forward the RUIP condition toward an infinite future provides the present value representation of the real exchange rate. As claimed by Engel and West (2005), the Beveridge and Nelson random-walk trend component of a near nonstationary economic fundamental, - the two-country differential in trend inflation in this model dominates the stochastic property of the real exchange rate. ${ }^{4}$ The real exchange rate then follows a near random-walk with a large volatility, as suggested by Engel and West's (2005) proposition. This main mechanism is preserved and even strengthened when allowing for a positive response of the Taylor rule to the output gap.

Under a plausible calibration a benchmark specification of the model indeed generates a highly persistent real exchange rate: the sum of the AR(5) roots is 0.992. As emphasized in the recent literature of real exchange rate dynamics including Eichenbaum and Evans (1995), Cheung and Lai (2000), Steinsson (2008), Iversen and Sönderstörm (2014), and Burstein and Gopinath (2014), the impulse response function (IRF) of the real exchange rate to a reduced-form shock is hump-shaped with a peak around a year and the corresponding half life of the real exchange rate is larger then four years. A decomposition of the IRF into structural shocks uncovers that the trend inflation shock even with a smaller standard deviation than those of the productivity shock and the conventional monetary policy shock dominates the amplification and propagation mechanism of the real exchange rate by generating a persistent hump-shaped IRF.

The benchmark specification also mimics a large volatility of the real exchange rate as in

\footnotetext{
${ }^{3}$ As discussed in Ascari and Sbordone (2014), price dispersion due to price stickiness is an important source of market distortion in this model. Especially, given the aggregate output level, price dispersion lowers the amount of consumption.

${ }^{4}$ The random-walk property of the nominal exchange rate within two-country general equilibrium models with explicit real money demand the functions is investigated by Nason and Rogers (2008) and, subsequently, Kano (2016).
} 
actual data. The simulated volatility ratio of the real currency return to the nominal one is close to one. The benchmark specification in fact implies an almost perfect correlation between the real and nominal currency returns. In other words, Mussa's (1986) well-known observation of the one-to-one correspondence between the real and nominal exchange rates is replicated in equilibrium. Moreover, when the benchmark model constricted under the flexible nominal exchange rate is allowed for a managed exchange rate regime, the volatility of the real exchange rate is dampened sharply, whereas the volatility of the inflation differential is unchanged significantly. Hence, the trend inflation model in this paper also approaches the Mussa puzzle plausibly. The results of the calibration exercises of this paper strongly support trend inflation as a relevant hypothesis for our better understanding of exchange rate dynamics.

The rest of the paper is organized as follows. Section 2 introduces the model. Section 3 derives an approximated analytical solution of the model under parametric assumptions. The approximated analytical solution proves random-walk property of the real exchange rate at the limiting case of a random-walk trend inflation. Section 4 reports the results of calibration exercises of this paper. Section 5 concludes.

\section{The model}

To extract implications of trend inflation for exchange rate dynamics as clearly as possible, I investigate a "plain vanilla" version of a two-country NK model equipped with Calvo-type sticky local currency pricing firms and Taylor-rule type monetary policies under an incomplete international financial markets. It is well-known that this canonical symmetric two-country NK model generates neither the persistence and volatility of the real exchange rates nor the one-to-one comovement of the real and nominal exchange rates as observed in actual data.

\subsection{Household sectors}

There are the home and foreign countries in this model. The two countries are endowed with the representative households whose objectives are the following lifetime utility functions

$$
\sum_{j=0}^{\infty} \beta^{j} E_{t}\left\{\ln C_{t+j}-\frac{\left(N_{t+j}\right)^{1+\eta}}{1+\eta}\right\} \quad \text { and } \sum_{j=0}^{\infty} \beta^{j} E_{t}\left\{\ln C_{t+j}^{*}-\frac{\left(N_{t+j}^{*}\right)^{1+\eta}}{1+\eta}\right\}
$$

for the home and foreign countries, respectively, where $C_{t}$ and $N_{t}$ represent the home country's consumption basket and hours worked and $C_{t}^{*}$ and $N_{t}^{*}$ are their foreign country's counterparts. For simplicity, I assume that the two countries share the identical lifetime utility specified by the same subjective discount factor $\beta \in(0,1)$ and the Frisch elasticity of labor supply $\eta>1 .^{5}$ Throughout this paper, any variable with the asterisk mark corresponds to a foreign variable, while a variable without the asterisk mark denotes the home counterpart.

\footnotetext{
${ }^{5}$ Because of stochastic trends due to permanent labor productivity shocks in the two countries, the model assumes the $\log$ utility functions over consumption to guarantee the existence of a balanced growth path in two-country equilibrium.
} 
The representative households in the two countries consume the home $(h)$ and foreign $(f)$ final goods. Home consumption basket $C_{t}$ consists of home and foreign product aggregators $C_{h, t}$ and $C_{f, t}$, while foreign consumption basket $C_{t}^{*}$ home and foreign product aggregators $C_{h, t}^{*}$ and $C_{f, t}^{*}$ :

$$
C_{t}=\left[\left(C_{h, t}\right)^{\frac{\zeta-1}{\zeta}}+\left(C_{f, t}\right)^{\frac{\zeta-1}{\zeta}}\right]^{\frac{\zeta}{\zeta-1}} \quad \text { and } \quad C_{t}^{*}=\left[\left(C_{h, t}^{*}\right)^{\frac{\zeta-1}{\zeta}}+\left(C_{f, t}^{*}\right)^{\frac{\zeta-1}{\zeta}}\right]^{\frac{\zeta}{\zeta-1}}
$$

where $\zeta>0$ is the elasticity of substitution between the home and foreign aggregators. ${ }^{6}$ The cost minimization problems of the home and foreign households derive the demand functions for $C_{h, t}$, $C_{f, t}, C_{h, t}^{*}$, and $C_{f, t}^{*}$ : for $j=\{h, f\}$

$$
C_{j, t}=\left(\frac{P_{j, t}}{P_{t}}\right)^{-\zeta} C_{t}, \quad \text { and } \quad C_{j, t}^{*}=\left(\frac{P_{j, t}^{*}}{P_{t}^{*}}\right)^{-\zeta} C_{t}^{*}
$$

where $P_{t}$ and $P_{t}^{*}$ are the aggregate consumer price indices (CPIs) of the home and foreign countries

$$
P_{t}=\left[\left(P_{h, t}\right)^{1-\zeta}+\left(P_{f, t}\right)^{1-\zeta}\right]^{\frac{1}{1-\zeta}} \text { and } P_{t}^{*}=\left[\left(P_{h, t}^{*}\right)^{1-\zeta}+\left(P_{f, t}^{*}\right)^{1-\zeta}\right]^{\frac{1}{1-\zeta}} .
$$

Here $P_{h, t}, P_{f, t}, P_{h, t}^{*}$, and $P_{f, t}^{*}$ are, respectively, the aggregate price over the home goods in the home country, that over the foreign goods in the home country, that over the home goods in the foreign country, and that over the foreign goods in the foreign country, as defined below.

The home and foreign aggregators of the home and foreign final goods, $C_{h, t}, C_{f, t}, C_{h, t}^{*}$, and $C_{f, t}^{*}$ consist of a continuum of the home and foreign final goods, each of which is produced by a monopolistically competitive firm residing either in the home or foreign countries, respectively. Each final good is placed within the unit interval $[0,1]$. The home and foreign final good aggregators in the home country are of the following Dixit and Stiglitz type: for $j=\{h, f\}$

$$
C_{j, t}=\left(\int_{0}^{1} C_{j, t}(z)^{\frac{\zeta-1}{\zeta}} d z\right)^{\frac{\zeta}{\zeta-1}} \text { and } C_{j, t}^{*}=\left(\int_{0}^{1} C_{j, t}(z)^{* \frac{\zeta-1}{\zeta}} d z\right)^{\frac{\zeta}{\zeta-1}}
$$

where $C_{j, t}(z)$ and $C_{j, t}(z)^{*}$ are the home and foreign demands for the particular home and foreign final goods indexed by $z \in[0,1]$, respectively. Here, $\zeta>0$ represents the elasticity of the demand for each final good with respect to its own price. ${ }^{7}$

The static cost-minimization problems of the representative households in the two countries derive the two countries' demand functions for the home and foreign final goods. Given the home and foreign prices of the home and foreign goods indexed by $z, P_{h, t}(z), P_{f, t}(z), P_{h, t}^{*}(z)$, and $P_{f, t}^{*}(z)$, they are

$$
C_{j, t}(z)=\left(\frac{P_{j, t}(z)}{P_{j, t}}\right)^{-\zeta} C_{j, t} \quad \text { and } \quad C_{j, t}^{*}(z)=\left(\frac{P_{j, t}^{*}(z)}{P_{j, t}^{*}}\right)^{-\zeta} C_{j, t}^{*}
$$

\footnotetext{
${ }^{6}$ In this paper, I assume no home bias over each country's consumption preference. Steinsson (2008) and Iversen and Söderström (2014), for example, exploit the home bias as an important propagation for real exchange rates.

${ }^{7}$ For simplicity, I assume the same price elasticity of the demand for an individual final product, $\zeta$, as that of the demand for an aggregate consumption basket.
} 
for $j=\{h, f\}$. Price aggregators $P_{h, t}, P_{f, t}, P_{h, t}^{*}$, and $P_{f, t}^{*}$ then are given as

$$
P_{j, t}=\left(\int_{0}^{1} P_{j, t}(z)^{1-\zeta} d z\right)^{\frac{1}{1-\zeta}} \text { and } P_{j, t}^{*}=\left(\int_{0}^{1} P_{j, t}^{*}(z)^{1-\zeta} d z\right)^{\frac{1}{1-\zeta}}
$$

for $j=\{h, f\}$.

The home representative household needs to satisfy the budget constraint in its maximization of the lifetime utility

$$
B_{h, t}+S_{t} B_{f, t}+P_{t} C_{t}=\left(1+i_{h, t-1}\right) B_{h, t-1}+S_{t}\left(1+i_{f, t-1}\right) B_{f, t-1}+W_{t} N_{t}+\Lambda_{t}
$$

where $B_{h, t}, B_{f, t}, i_{h, t}, i_{f, t}, W_{t}, \Lambda_{t}$, and $S_{t}$ denote the home country's holding of the home country's nominal bonds, the home country's holding of the foreign country's nominal bonds, the home county's nominal interest rate for the home country's bonds, the home county's nominal interest rate for the foreign country's bonds, the home country's nominal wage, the static profit from the home country's monopolistically competitive firms, and the level of the bilateral nominal exchange rate of the home currency per the foreign country, respectively. Similarly, the representative household in the foreign country maximizes its lifetime utility subject to the following budget constraint

$$
\frac{B_{h, t}^{*}}{S_{t}}+B_{f, t}^{*}+P_{t}^{*} C_{t}^{*}=\left(1+i_{h, t-1}^{*}\right) \frac{B_{h, t-1}^{*}}{S_{t}}+\left(1+i_{f, t-1}^{*}\right) B_{f, t-1}^{*}+W_{t}^{*} N_{t}^{*}+\Lambda_{t}^{*}
$$

where $B_{h, t}^{*}, B_{f, t}^{*}, i_{h, t}^{*}, i_{f, t}^{*}, W_{t}^{*}$ and $\Lambda_{t}^{*}$ denote the foreign country's holding of the home country's nominal bonds, the foreign country's holding of the foreign country's nominal bonds, the foreign county's nominal interest rate for the home country's bonds, the foreign county's nominal interest rate for the foreign country's bonds, the foreign country's nominal wage, and the static profit from the foreign country's monopolistically competitive final good firms.

The first order necessary conditions (FONCs) for the home and foreign households' lifetime utility maximization problems consist of the home and foreign Euler equations

$$
\frac{1}{P_{t} C_{t}}=\beta\left(1+i_{h, t}\right) E_{t} \frac{1}{P_{t+1} C_{t+1}} \quad \text { and } \quad \frac{1}{P_{t}^{*} C_{t}^{*}}=\beta\left(1+i_{f, t}^{*}\right) E_{t} \frac{1}{P_{t+1}^{*} C_{t+1}^{*}},
$$

the home and foreign utility-based uncovered interest parity conditions (UIPs),

$$
E_{t} \frac{1}{P_{t+1} C_{t+1}}\left\{\left(1+i_{h, t}\right)-\left(1+i_{f, t}\right) \frac{S_{t+1}}{S_{t}}\right\}=0 \quad \text { and } \quad E_{t} \frac{1}{P_{t+1}^{*} C_{t+1}^{*}}\left\{\left(1+i_{f, t}^{*}\right)-\left(1+i_{h, t}^{*}\right) \frac{S_{t}}{S_{t+1}}\right\}=0
$$

and the home and foreign intratemporal optimality conditions for hours worked

$$
N_{t}^{\eta}=\frac{W_{t}}{P_{t} C_{t}} \quad \text { and } \quad N_{t}^{* \eta}=\frac{W_{t}^{*}}{P_{t}^{*} C_{t}^{*}} .
$$

Finally, suitable transversality conditions for international bond holdings should be satisfied.

\subsection{Final good sectors}


Facing the corresponding demand functions, final good firm $z \in[0,1]$ acts as an identical monopolistically competitive price setter. When setting its current optimal price, each firm follows the Calvo (1983) type time-dependent pricing strategy: in each period, a firm cannot reset its optimal price with a probability $\mu \in(0,1]$. Moreover, to generate endogenous fluctuations of the real exchange rate, I assume that all the firms adopt the local currency pricing (LCP) strategy as in Betts and Devereux (1996, 2000): each firm sets its optimal price differently between the two countries in terms of the local currencies.

Under the LCP-Calvo pricing strategy, the objective function of a home firm is

$$
\begin{aligned}
\max _{\mathbf{P}_{h, t}, \mathbf{P}_{h, t}^{*}} E_{t} \sum_{i=0}^{\infty} \mu^{i} \Gamma_{t+i}\left\{\left(\frac{\mathbf{P}_{h, t}}{P_{h, t+i}}\right)-m c_{t+i}\right\} & \left(\frac{\mathbf{P}_{h, t}}{P_{h, t+i}}\right)^{-\zeta} C_{h, t+i} \\
& +E_{t} \sum_{i=0}^{\infty} \mu^{i} \Gamma_{t+i}\left\{\left(\frac{S_{t+i} \mathbf{P}_{h, t}^{*}}{P_{h, t+i}}\right)-m c_{t+i}\right\}\left(\frac{\mathbf{P}_{h, t}^{*}}{P_{h, t+i}^{*}}\right)^{-\zeta} C_{h, t+i}^{*},
\end{aligned}
$$

where $\mathbf{P}_{h, t}, \mathbf{P}_{h, t}^{*}, m c_{t}$, and $\Gamma_{t}$ are the optimal price of the home good in the home country, the optimal price of the home good in the foreign country, the real marginal cost of the home firm, and the home country's stochastic discount factor $\Gamma_{t+i} \equiv \beta^{i}\left(P_{t} / P_{t+i}\right)\left(C_{t} / C_{t+i}\right)$. Similarly, the objective function of a foreign firm is

$$
\begin{aligned}
\max _{\mathbf{P}_{f, t}, \mathbf{P}_{f, t}^{*}} E_{t} \sum_{i=0}^{\infty} \mu^{i} \Gamma_{t+i}^{*}\left\{\left(\frac{\mathbf{P}_{f, t}}{S_{t+i} P_{f, t+i}^{*}}\right)-\right. & \left.m c_{t+i}^{*}\right\}\left(\frac{\mathbf{P}_{f, t}}{P_{f, t+i}}\right)^{-\zeta} C_{f, t+i} \\
& +E_{t} \sum_{i=0}^{\infty} \mu^{i} \Gamma_{t+i}^{*}\left\{\left(\frac{\mathbf{P}_{f, t}^{*}}{P_{f, t+i}^{*}}\right)-m c_{t+i}^{*}\right\}\left(\frac{\mathbf{P}_{f, t}^{*}}{P_{f, t+i}^{*}}\right)^{-\zeta} C_{f, t+i}^{*}
\end{aligned}
$$

where $\mathbf{P}_{f, t}, \mathbf{P}_{f, t}^{*}, m c_{t}^{*}$, and $\Gamma_{t}^{*}$ are the optimal price of the foreign good in the home country, the optimal price of the foreign good in the foreign country, the real marginal cost of the foreign firm, and the foreign country's stochastic discount factor $\Gamma_{t+i}^{*}=\beta\left(P_{t}^{*} / P_{t+1}^{*}\right)\left(C_{t}^{*} / C_{t+i}^{*}\right)$.

The FONCs for the optimal prices the home firm sets for the home and foreign countries are

$$
\begin{aligned}
& \mathbf{P}_{h, t} E_{t} \sum_{i=0}^{\infty} \mu^{i} \Gamma_{t+i}\left(\frac{1}{P_{h, t+i}}\right)^{1-\zeta} C_{h, t+i}=\frac{\zeta}{\zeta-1} E_{t} \sum_{i=0}^{\infty} \mu^{i} \Gamma_{t+i} m c_{t+i}\left(\frac{1}{P_{h, t+i}}\right)^{-\zeta} C_{h, t+i}, \\
& \mathbf{P}_{h, t}^{*} E_{t} \sum_{i=0}^{\infty} \mu^{i} \Gamma_{t+i}\left(\frac{S_{t+i} P_{h, t+i}^{*}}{P_{h, t+i}}\right)\left(\frac{1}{P_{h, t+i}^{*}}\right)^{1-\zeta} C_{h, t+i}^{*}=\frac{\zeta}{\zeta-1} E_{t} \sum_{i=0}^{\infty} \mu^{i} \Gamma_{t+i} m c_{t+i}\left(\frac{1}{P_{h, t+i}^{*}}\right)^{-\zeta} C_{h, t+i}^{*},
\end{aligned}
$$

respectively. Similarly, the FONCs for the optimal prices the foreign firm for the home and foreign 
countries are

$$
\begin{aligned}
& \mathbf{P}_{f, t} E_{t} \sum_{i=0}^{\infty} \mu^{i} \Gamma_{t+i}^{*}\left(\frac{P_{f, t+i}}{S_{t+i} P_{f, t+i}^{*}}\right)\left(\frac{1}{P_{f, t+i}}\right)^{1-\zeta} C_{f, t+i}=\frac{\zeta}{\zeta-1} E_{t} \sum_{i=0}^{\infty} \mu^{i} \Gamma_{t+i}^{*} m c_{t+i}^{*}\left(\frac{1}{P_{f, t+i}}\right)^{-\zeta} C_{f, t+i}, \\
& \mathbf{P}_{f, t}^{*} E_{t} \sum_{i=0}^{\infty} \mu^{i} \Gamma_{t+i}^{*}\left(\frac{1}{P_{f, t+i}^{*}}\right)^{1-\zeta} C_{f, t+i}^{*}=\frac{\zeta}{\zeta-1} E_{t} \sum_{i=0}^{\infty} \mu^{i} \Gamma_{t+i}^{*} m c_{t+i}^{*}\left(\frac{1}{P_{f, t+i}^{*}}\right)^{-\zeta} C_{f, t+i}^{*} .
\end{aligned}
$$

Given the optimal prices, the price aggregators $P_{h, t}, P_{f, t}, P_{h, t}^{*}$, and $P_{f, t}^{*}$ follow the laws of motion

$$
P_{j, t}^{1-\zeta}=(1-\mu) \mathbf{P}_{j, t}^{1-\zeta}+\mu P_{j, t-1}^{1-\zeta}, \quad \text { and } \quad P_{j, t}^{* 1-\zeta}=(1-\mu) \mathbf{P}_{j, t}^{* 1-\zeta}+\mu P_{j, t-1}^{* 1-\zeta}
$$

where $j=\{h, f\}$.

In this paper, I assume that each final good firm produces its product using only labor input hired from the domestic competitive labor market. The production functions of the home and foreign goods are $Y_{t}(z)=A_{t} L_{t}(z)$ and $Y_{t}^{*}(z)=A_{t}^{*} L_{t}^{*}(z)$, where $A_{t}$ and $A_{t}^{*}$ are the labor productivities in the home and foreign countries. In this case, the real marginal costs the home and foreign firms face are, respectively,

$$
m c_{t}=\frac{W_{t}}{A_{t} P_{h, t}} \quad \text { and } \quad m c_{t}^{*}=\frac{W_{t}^{*}}{A_{t}^{*} P_{f, t}^{*}} .
$$

The home and foreign static profits are

$$
\begin{aligned}
\Lambda_{t} & \equiv \int_{0}^{1}\left\{P_{h, t}(z) C_{h, t}(z)+S_{t} P_{h, t}^{*}(z) C_{h, t}^{*}(z)-W_{t} N_{t}(z)\right\} d z \\
& =P_{h, t}\left(\frac{P_{h, t}}{P_{t}}\right)^{-\zeta} C_{t}+S_{t} P_{h, t}^{*}\left(\frac{P_{h, t}^{*}}{P_{t}^{*}}\right)^{-\zeta} C_{t}^{*}-W_{t} N_{t}, \\
S_{t} \Lambda_{t}^{*} & \equiv \int_{0}^{1}\left\{P_{f, t}(z) C_{f, t}(z)+S_{t} P_{f, t}^{*}(z) C_{f, t}^{*}(z)-S_{t} W_{t}^{*} N_{t}(z)^{*}\right\} d z \\
& =P_{f, t}\left(\frac{P_{f, t}}{P_{t}}\right)^{-\zeta} C_{t}+S_{t} P_{f, t}^{*}\left(\frac{P_{f, t}^{*}}{P_{t}^{*}}\right)^{-\zeta} C_{t}^{*}-S_{t} W_{t}^{*} N_{t}^{*},
\end{aligned}
$$

respectively.

\subsection{Monetary policies with trend inflations}

The monetary policies in the two countries are characterize by Taylor rules. The central banks of the two countries set their short-term domestic nominal interest rate $\left(1+i_{h, t}\right)$ and $(1+$ $\left.i_{f, t}^{*}\right)$ depending on the past interest rate levels, $\left(1+i_{h, t-1}\right)$ and $\left(1+i_{f, t-1}^{*}\right)$, the current inflation rates, $\gamma_{\pi, t} \equiv P_{t} / P_{t-1}$ and $\gamma_{\pi, t}^{*} \equiv P_{t}^{*} / P_{t-1}^{*}$, and the detrended output levels, $y_{t} \equiv Y_{t} / A_{t}$ and $y_{t}^{*} \equiv$ $Y_{t}^{*} / A_{t}^{*}$, respectively. In this paper, I further allow for exogenous slow-moving trend inflations $\gamma_{\tau, t} \equiv P_{\tau, t} / P_{\tau, t-1}$ and $\gamma_{\tau, t}^{*} \equiv P_{\tau, t}^{*} / P_{\tau, t-1}^{*}$ in the two countries, where $P_{\tau, t}$ and $P_{\tau, t}^{*}$ are the exogenous permanent components of the aggregate price levels of the two countries generated by the trend inflations. As argued by Ireland (2007), the central banks of the two countries target the trend 
inflation levels:

$$
\begin{aligned}
& \left(1+i_{h, t}\right)=(1+i)^{1-\rho_{i}}\left(1+i_{h, t-1}\right)^{\rho_{i}}\left(\frac{\gamma_{\pi, t}}{\gamma_{\tau, t}}\right)^{a_{\pi}}\left(y_{t}\right)^{a_{y}} \exp \left(\epsilon_{i, t}\right), \\
& \left(1+i_{f, t}^{*}\right)=\left(1+i^{*}\right)^{1-\rho_{i}}\left(1+i_{f, t-1}^{*}\right)^{\rho_{i}}\left(\frac{\gamma_{\pi, t}^{*}}{\gamma_{\tau, t}^{*}}\right)^{a_{\pi}}\left(y_{t}^{*}\right)^{a_{y}} \exp \left(\epsilon_{i, t}^{*}\right),
\end{aligned}
$$

where $i$ and $i^{*}$ are the deterministic steady state values of the home and foreign nominal interest rates and $\rho_{i} \in(0,1)$ captures the degree of the interest rate smoothing. The condition of $a_{\pi}>1$ is well known as the Taylor principle that is necessary for the unique equilibrium in this model. $\epsilon_{i, t}$ and $\epsilon_{i, t}^{*}$ are i.i.d. monetary policy shocks in the home and foreign countries. Finally, the trend inflation rates $\gamma_{\tau, t}$ and $\gamma_{\tau, t}^{*}$ follow $\operatorname{AR}(1)$ processes in the log term:

$$
\ln \gamma_{\tau, t}=\left(1-\rho_{\tau}\right) \ln \gamma_{\tau}+\rho_{\tau} \ln \gamma_{\tau, t-1}+\epsilon_{\tau, t} \quad \text { and } \quad \ln \gamma_{\tau, t}^{*}=\left(1-\rho_{\tau}\right) \ln \gamma_{\tau}+\rho_{\tau} \ln \gamma_{\tau, t-1}^{*}+\epsilon_{\tau, t}^{*},
$$

where $\gamma_{\tau}$ is the common long-run mean of the trend inflation rate, $\rho_{\tau} \in[0,1)$ is the $\operatorname{AR}(1)$ root of the trend inflation rate, and $\epsilon_{\tau, t}$ and $\epsilon_{\tau, t}^{*}$ are i.i.d. trend inflation shocks. As in a closed-economy NK model by Ascari and Sbordone (2014), the time-invariant common unconditional mean $\gamma_{\tau}$ makes the log-linearization exercise of this paper tractable when characterizing the deterministic steady state. ${ }^{8}$ Taking a difference between the two equations of the two countries's trend inflations yields the stochastic process of the trend inflation differential

$$
\ln \gamma_{\tau, t}^{d}=\rho_{\tau} \ln \gamma_{\tau, t-1}^{d}+\epsilon_{\tau, t}^{d},
$$

where $\epsilon_{\tau, t}^{d} \equiv \epsilon_{\tau, t}-\epsilon_{\tau, t}^{*}$. Below I scrutinize implications of I(1) trend inflation differential on the equilibrium of the model by taking the limit of the unit root, $\rho_{\tau} \rightarrow 1$.

\subsection{Market clearing and productivity shocks}

To guarantee a stationary distribution of the net foreign asset positions of the two countries within incomplete international financial markets, I allow for a debt-elastic risk premium in the interest rates faced only by the home country: for $j=\{h, f\}$

$$
i_{j, t}=i_{j, t}^{*}\left[1+\psi\left\{\exp \left(-b_{j, t}+\bar{d}\right)-1\right\}\right], \quad \bar{d} \leq 0, \quad \psi>0,
$$

where $b_{j, t}$ is the transitory component of the home country's holdings of country $j$ 's bonds, which is precisely defined below. Notice that the home country needs to pay a risk premium over the interest rate level the foreign household faces when the transitory components of the home country's net borrowing positions $b_{j, t}<0$ is beyond its threshold level $\bar{d}$. The risk premium is given as an externality: the household does not take into account the effect of the debt position on the risk premium when maximizing the lifetime utility function. On the other hand, we do not attach a risk premium to foreign country's interest rates..$^{9}$

\footnotetext{
${ }^{8}$ Ascari and Sbordone (2014) do not allow for stochastic variations in trend inflation. To the contrary, Cogley and Sbordone (2008) investigate a time-varying stochastic steady state with I(1) trend inflation.

${ }^{9}$ Since the elasticity of the risk premium toward the debt position, $\psi$, is set to a very small number, this asymmetric treatment of the debt elastic risk premium between the home and foreign countries does not affect the equilibrium
} 
The market-clearing conditions of the two countries' bond markets are

$$
B_{h, t}+B_{h, t}^{*}=0 \quad \text { and } \quad B_{f, t}+B_{f, t}^{*}=0,
$$

i.e., along an equilibrium path, the world net supply of nominal bonds is zero on a period-by-period basis. The market clearing conditions of the home and foreign final goods are

$$
\begin{aligned}
& A_{t} N_{t}=\int_{0}^{1}\left\{C_{h, t}(z)+C_{h, t}^{*}(z)\right\} d z=\Omega_{h, t} C_{h, t}+\Omega_{h, t}^{*} C_{h, t}^{*}, \\
& A_{t}^{*} N_{t}^{*}=\int_{0}^{1}\left\{C_{f, t}(z)+C_{f, t}^{*}(z)\right\} d z=\Omega_{f, t} C_{f, t}+\Omega_{f, t}^{*} C_{f, t}^{*},
\end{aligned}
$$

where the variables

$$
\Omega_{j, t} \equiv \int_{0}^{1}\left(\frac{P_{j, t}(z)}{P_{t}}\right)^{-\zeta} d z, \quad \text { and } \quad \Omega_{j, t}^{*} \equiv \int_{0}^{1}\left(\frac{P_{j, t}^{*}(z)}{P_{t}^{*}}\right)^{-\zeta} d z, \quad \text { for } j=h, f
$$

capture the degrees of price dispersions in the four final good markets. As discussed by Ascari and Sbordone (2014), the price dispersion variables are greater than one under price stickiness, but are one if all the prices are identical within each final goods market in each country under flexible price adjustments. The market clearing conditions then imply that variables $\Omega_{j, t}$ and $\Omega_{j, t}^{*}$ represent the resource costs of price dispersion: given the output level, the higher the price dispersion variable, the lower the amount allocated to consumption. The price dispersion variables then follow the transitions

$$
\begin{aligned}
& \Omega_{j, t}=(1-\mu)\left(\frac{\mathbf{P}_{j, t}}{P_{t}}\right)^{-\zeta}+\mu\left(\frac{P_{j, t}}{P_{j, t-1}}\right)^{\zeta} \Omega_{j, t-1}, \\
& \Omega_{j, t}^{*}=(1-\mu)\left(\frac{\mathbf{P}_{j, t}^{*}}{P_{t}^{*}}\right)^{-\zeta}+\mu\left(\frac{P_{j, t}^{*}}{P_{j, t-1}^{*}}\right)^{\zeta} \Omega_{j, t-1}^{*},
\end{aligned}
$$

for $j=h, f{ }^{10}$

I assume that the logarithms of the labor productivities, $\ln A_{t}$ and $\ln A_{t}^{*}$, are of I(1). To guarantee a balanced growth path of this two country model, I assume that the labor productivity differential $\ln a_{t} \equiv \ln A_{t}-\ln A_{t}^{*}$ is of I(0). Notice that the I(1) labor productivities and the stationary productivity differential jointly imply that the labor productivity of the home country must be cointegrated with that of the foreign country. The home and foreign growth rates of the labor productivity, $\gamma_{A, t} \equiv \ln A_{t}-\ln A_{t-1}$ and $\gamma_{A, t}^{*} \equiv \ln A_{t}^{*}-\ln A_{t-1}^{*}$, follow

$$
\gamma_{A, t}=\ln \gamma_{A}-\frac{\lambda}{2} \ln a_{t-1}+\epsilon_{A, t}, \quad \text { and } \quad \gamma_{A, t}^{*}=\ln \gamma_{A}+\frac{\lambda}{2} \ln a_{t-1}+\epsilon_{A, t}^{*},
$$

where $\gamma_{A}>1$ is the common drift term and $\lambda \in[0,1)$ is the adjustment speed of the error correction

\footnotetext{
outcome much.

${ }^{10}$ The full derivation of the transition equations of the price dispersion variables is found in Ascari and Sbordone (2014).
} 
mechanism. The error correction mechanism implies that the cross-country labor productivity differential is of $\mathrm{I}(0)$ because

$$
\ln a_{t}=(1-\lambda) \ln a_{t-1}+\epsilon_{A, t}^{d},
$$

where $\epsilon_{A, t}^{d} \equiv \epsilon_{A, t}-\epsilon_{A, t}^{*}$. Importantly, if the adjustment speed $\lambda$ is sufficiently close to zero, the cross-country labor productivity differential can be realized near I(1).

Because the model contains non-stationary components $A_{t}, A_{t}^{*}, P_{\tau, t}$, and $P_{\tau, t}^{*}$, I stochastically de-trend the FONCs by these stochastic trend components to characterize the unique deterministic steady state, as shown in the accompanying appendix in detail. ${ }^{11}$ In doing so, define the stochastically detrended versions of the home consumption by $c_{t} \equiv C_{t} / A_{t}$; the foreign consumption $c_{t}^{*} \equiv C_{t}^{*} / A_{t}^{*}$; the home price of home goods $p_{h, t} \equiv P_{h, t} A_{t} / P_{\tau, t}$; the home price of foreign goods $p_{f, t} \equiv P_{f, t} A_{t} / P_{\tau, t}$; the foreign price of home goods $p_{h, t}^{*} \equiv P_{h, t}^{*} A_{t}^{*} / P_{\tau, t}^{*}$; the foreign price of foreign goods $p_{f, t}^{*} \equiv P_{f, t}^{*} A_{t}^{*} / P_{\tau, t}^{*}$; the optimal home price of home goods $\mathbf{p}_{h, t} \equiv \mathbf{P}_{h, t} A_{t} / P_{\tau, t}$; the optimal home price of foreign goods $\mathbf{p}_{f, t} \equiv \mathbf{P}_{f, t} A_{t} / P_{\tau, t}$; the optimal foreign price of home goods $\mathbf{p}_{h, t}^{*} \equiv \mathbf{P}_{h, t}^{*} A_{t}^{*} / P_{\tau, t}^{*}$; the optimal foreign price of foreign goods $\mathbf{p}_{f, t}^{*} \equiv \mathbf{P}_{f, t}^{*} A_{t}^{*} / P_{\tau, t}^{*}$; the home CPI $p_{t} \equiv P_{t} A_{t} / P_{\tau, t}$; the foreign CPI $p_{t}^{*} \equiv P_{t}^{*} A_{t}^{*} / P_{\tau, t}^{*}$; the home holding of the home bond $b_{h, t}=B_{h, t} / P_{\tau, t}$; the home holding of the foreign bond $b_{f, t}=B_{f, t} / P_{\tau, t}^{*}$; the foreign holding of the home bond $b_{h, t}^{*}=B_{h, t}^{*} / P_{\tau, t}$; the foreign holding of the foreign bond $b_{f, t}^{*} \equiv B_{f, t}^{*} / P_{\tau, t}^{*}$; the home nominal wage $w_{t} \equiv W_{t} / P_{\tau, t}$; the foreign nominal wage $w_{t}^{*} \equiv W_{t}^{*} / P_{\tau, t}^{*}$; the nominal exchange rate $s_{t} \equiv S_{t} P_{\tau, t}^{*} / P_{\tau, t}$. The real exchange rate is given by $q_{t} \equiv S_{t} P_{t}^{*} / P_{t}=s_{t} a_{t} p_{t}^{*} / p_{t}$. To derive the corresponding linear rational expectations (LRE) models, I take a log-linear approximation of the stochastically detrended FONCs around the unique deterministic steady state. For a variable $x_{t}$, let $\hat{x}_{t}$ denote the percentage deviation from its deterministic steady state value $x$, i.e., $\hat{x}_{t} \equiv\left(x_{t}-x\right) / x$, and $\tilde{x}_{t}$ the deviation from the deterministic steady state vale, i.e, $\tilde{x}_{t} \equiv x_{t}-x$, respectively.

For simplicity, I assume symmetric two countries with $\bar{d}=0$ throughout this paper. In this case, the deviation from the law of one price is also symmetric across the home and foreign goods:

$$
\hat{q}_{t}=\hat{s}_{t}+\hat{a}_{t}+\hat{p}_{h, t}^{*}-\hat{p}_{h, t}, \quad \text { and } \quad \hat{q}_{t}=\hat{s}_{t}+\hat{a}_{t}+\hat{p}_{f, t}^{*}-\hat{p}_{f, t}^{*}
$$

Hence, $\hat{p}_{h, t}-\hat{p}_{h, t}^{*}=\hat{p}_{f, t}-\hat{p}_{f, t}^{*}$, i.e., the cross-country price differential is identical across the home and foreign goods. Moreover, from the home and foreign CPIs, this condition implies $\hat{p}_{t}-\hat{p}_{t}^{*}=\hat{p}_{h, t}-\hat{p}_{h, t}^{*}=$ $\hat{p}_{f, t}-\hat{p}_{f, t}^{*}$, i.e., the cross-country CPI differential is also identical with the price differentials of the individual goods across the two countries.

\subsection{A generalized New Keynesian Phillips curve with trend inflation}

The accompanying appendix shows the whole derivation of the GNKPCs for the home good price inflation at the home country, $\hat{\pi}_{h, t}=\hat{p}_{h, t}-\hat{p}_{h, t-1}$. Under the parameter definitions of $\varphi_{1} \equiv$ $\beta \mu\left(\gamma_{\tau} / \gamma_{A}\right)^{\zeta-2} \in(0,1), \varphi_{2} \equiv \beta \mu\left(\gamma_{\tau} / \gamma_{A}\right)^{\zeta-1} \in(0,1)$, and $\varphi_{0} \equiv \frac{1-\beta^{-1} \varphi_{2}}{\beta^{-1} \varphi_{2}}$, the corresponding GNKPC

\footnotetext{
${ }^{11}$ The appendix is available upon request.
} 


$$
\begin{aligned}
& \hat{\pi}_{h, t}+ \hat{\gamma}_{\tau, t}-\hat{\gamma}_{A, t}=-\frac{\varphi_{0}\left(\varphi_{1}-\varphi_{2}\right)}{\varphi_{1}} \zeta \sum_{i=1}^{\infty} \varphi_{1}^{i} E_{t}\left(\hat{\pi}_{t+i}-\hat{\pi}_{h, t+i}\right)+\varphi_{0}\left(1-\varphi_{2}\right) \hat{m} c_{t} \\
&+\varphi_{2}\left(1+\varphi_{0}\right) E_{t}\left(\hat{\pi}_{h, t+1}+\hat{\gamma}_{\tau, t+1}-\hat{\gamma}_{A, t+1}\right)+\frac{\varphi_{0}\left(\varphi_{1}-\varphi_{2}\right)}{\varphi_{1}} \sum_{i=1}^{\infty} \varphi_{1}^{i} E_{t}\left(\hat{\pi}_{t+i}+\hat{\gamma}_{\tau, t+i}-\hat{\gamma}_{A, t+i}\right) \\
& \quad-\frac{\varphi_{0}\left(\varphi_{1}-\varphi_{2}\right)}{\varphi_{1}}(\zeta-1) \sum_{i=1}^{\infty} \varphi_{1}^{i} E_{t}\left(\hat{\pi}_{h, t+i}+\hat{\gamma}_{\tau, t+i}-\hat{\gamma}_{A, t+i}\right) .
\end{aligned}
$$

Therefore, as claimed by Cogley and Sbordone (2008), GNKPC (3) depends on higher-order leads of the home good price inflation as well as the home CPI inflation. Moreover, although no time-varying coefficient founded in Cogley and Sbordone (2008) is allowed for in this model, coefficients $\varphi_{0}, \varphi_{1}$, and $\varphi_{2}$ depend on primitives $\beta, \mu, \gamma_{\tau}$, and $\gamma_{A}$. In particular, a higher steady state trend inflation relative to productivity growth $\gamma_{\tau} / \gamma_{A}$ implies a lower weight on the current real marginal cost $\hat{m} c_{t}$, a higher weight on the expected future home good price inflation $E_{t}\left(\hat{\pi}_{h, t+i}+\hat{\gamma}_{\tau, t+i}-\hat{\gamma}_{A, t+i}\right)$, and a lower weight on the expected future home CPI inflation $E_{t}\left(\hat{\pi}_{t+i}+\hat{\gamma}_{\tau, t+i}-\hat{\gamma}_{A, t+i}\right)$ for $i=1,2, \ldots .{ }^{12}$

The appendix also displays the full derivation of the GNKPC for the home good price inflation at the foreign country, $\hat{\pi}_{h, t}^{*} \equiv \hat{p}_{h, t}^{*}-\hat{p}_{h, t-1}^{*}$. Notice that under the assumption of symmetric twocountries, $\hat{\pi}_{t}-\hat{\pi}_{t}^{*}=\hat{\pi}_{h, t}-\hat{\pi}_{h, t}^{*}=\hat{\pi}_{f, t}-\hat{\pi}_{f, t}^{*}$. For exposition, define the cross-country difference variables $x_{t}^{d} \equiv x_{t}-x_{t}^{*}$ for any home and foreign variables $x_{t}$ and $x_{t}^{*}$. Subtracting the GNKPC of $\hat{\pi}_{h, t}^{*}$ from that of $\hat{\pi}_{h, t}$ then provides the following GNKPC for the inflation differential between the two countries $\hat{\pi}_{t}^{d}$ :

$$
\begin{array}{r}
\hat{\pi}_{t}^{d}+\hat{\gamma}_{\tau, t}^{d}-\hat{\gamma}_{A, t}^{d}=\varphi_{0}\left(1-\varphi_{2}\right) \hat{a}_{t}+\frac{\varphi_{0} \varphi_{2}\left(1-\varphi_{1}\right)}{\varphi_{1}}\left(\hat{q}_{t}-\hat{a}_{t}\right)+\varphi_{2}\left(1+\varphi_{0}\right) E_{t}\left(\hat{\pi}_{t+1}^{d}+\hat{\gamma}_{\tau, t+1}^{d}-\hat{\gamma}_{A, t+1}^{d}\right) \\
-\frac{\varphi_{0}\left(\varphi_{1}-\varphi_{2}\right)(\zeta-1)}{\varphi_{1}} \sum_{i=1}^{\infty} \varphi_{1}^{i} E_{t}\left(\hat{\pi}_{t+i}^{d}+\hat{\gamma}_{\tau, t+i}^{d}+\hat{\gamma}_{A, t+i}^{d}\right)+\frac{\varphi_{0}\left(\varphi_{1}-\varphi_{2}\right)}{\varphi_{1}} \sum_{i=1}^{\infty} \varphi_{1}^{i} E_{t} \Delta \hat{c}_{t+i}^{d} \\
+\frac{\varphi_{0}\left(\varphi_{1}-\varphi_{2}\right)\left(1-\varphi_{1}\right)}{\varphi_{1}} \sum_{i=0}^{\infty} \varphi_{1}^{i} E_{t}\left(\hat{q}_{t+i}-\hat{a}_{t+i}\right) .
\end{array}
$$

Observe that under the condition $\gamma_{\tau}=\gamma_{A}$ the GNKPC for the inflation differential, eq. (4), will be

\footnotetext{
${ }^{12}$ Observe that GNKPC (3) turns out to be the conventional NKPC under the restrictive parameterization of $\gamma_{\tau}=\gamma_{A}$. Because in this case $\varphi_{1}=\varphi_{2}=\beta \mu$ and $\varphi_{0}=(1-\mu) / \mu$, the first, fourth, and fifth terms in the RHS of eq.(3) vanish and the conventional NKPC of the home good price inflation $\Delta \ln P_{h, t}$ emerges:

$$
\Delta \ln P_{h, t}=\beta E_{t} \Delta \ln P_{h, t+1}+\kappa_{\mu} \hat{m} c_{t}
$$

where $\kappa_{\mu} \equiv \frac{(1-\mu)(1-\beta \mu)}{\mu} \in(0,1)$ and $\Delta \equiv 1-L$ is the first difference operator. Hence, GNKPC (3) nests the standard NKPC under the restrictive parametalization of $\gamma_{\tau}=\gamma_{A}$. Notice that the standard open-economy NK model investigated in the literature of the PPP puzzle such as Chari et al.(2002) and Benigno (2004) allows for no stochastic trend of either productivity growth or inflation, i.e., $\gamma_{A}=\gamma_{\tau}=1$. Therefore, GNKPC in this model implies richer and more persistent dynamics of the domestic inflation than that in the conventional models.
} 
simplified as

$$
\Delta \ln P_{t}^{d}=\beta E_{t} \Delta \ln P_{t+1}^{d}+\kappa_{\mu} \hat{q}_{t} .
$$

where $\kappa_{\mu} \equiv \frac{(1-\mu)(1-\beta \mu)}{\mu} \in(0,1)$ and $\Delta \equiv 1-L$ is the first difference operator. Under this restrictive case, the current inflation differential depends on the one-period ahead expected inflation differential and the real exchange rate. ${ }^{13}$ On the other hand, the current inflation differential in this model depends not only on the current real exchange rate and the one-period ahead expected inflation differential but also on the expectations of higher order leads of the future real exchange rates and the future inflation differentials. As discussed by Cogley and Sbordone (2008), this characteristic yields a more persistent process of the inflation differential than that in the standard case with $\gamma_{\tau}=\gamma_{A}=1$.

\subsection{Terms of trade dynamics}

Another important relative price in this model is the terms of trade (TOT). Let $\Psi_{t}$ and $\Psi_{t}^{*}$ denote the terms of trade in the home and foreign countries, i.e., the relative price of the home good to the foreign good in the home country, $\Psi_{t} \equiv P_{h, t} / P_{f, t}=p_{h, t} / p_{f, t}$ and that of the foreign good to the home good in the foreign country, $\Psi_{t}^{*} \equiv P_{f, t}^{*} / P_{h, t}^{*}=p_{f, t}^{*} / p_{h, t}^{*}$. Recall that under the symmetric equilibrium, $\frac{P_{f, t}}{P_{h, t}}=\frac{P_{f, t}^{*}}{P_{h, t}^{*}}$ and, hence, $\Psi_{t}=1 / \Psi_{t}^{*}$. Below I focus only on the dynamics of the home $\operatorname{TOT} \Psi_{t}$.

The log linear approximation of the home TOT is $\hat{\Psi}_{t}=\hat{p}_{h, t}-\hat{p}_{f, t}$. Hence, the growth rate of the home TOT is simply the inflation differential between the home good price and the foreign good price in the home country: $\Delta \hat{\Psi}_{t}=\hat{\pi}_{h, t}-\hat{\pi}_{f, t}$. The appendix derives the GNKPC for the foreign good price inflation in the home country $\hat{\pi}_{f, t} \equiv \hat{p}_{f, t}-\hat{p}_{f, t-1}$. Subtracting the GNKPC of $\hat{\pi}_{f, t}$ from that for $\hat{\pi}_{h, t}$, eq.(3) and rearranging the result provides the TOT dynamics

$$
\begin{gathered}
\Delta \hat{\Psi}_{t}=\varphi_{0}\left(1-\varphi_{2}\right)\left(\hat{m} c_{t}^{d}-\hat{a}_{t}\right)+\varphi_{2}\left(1+\varphi_{0}\right) E_{t} \Delta \hat{\Psi}_{t+1}-\frac{\varphi_{0} \varphi_{2}\left(1-\varphi_{1}\right)}{\varphi_{1}}\left(\hat{q}_{t}-\hat{a}_{t}\right) \\
+\frac{\varphi_{0}\left(\varphi_{1}-\varphi_{2}\right)}{\varphi_{1}} \sum_{i=1}^{\infty} \varphi_{1}^{i} E_{t} \Delta \hat{\Psi}_{t+i}+\frac{\varphi_{0}\left(\varphi_{1}-\varphi_{2}\right)}{\varphi_{1}} \sum_{i=1}^{\infty} \varphi_{1}^{i} E_{t} \Delta \hat{c}_{t+i}^{d} \\
-\frac{\varphi_{0}\left(\varphi_{1}-\varphi_{2}\right)\left(1-\varphi_{1}\right)}{\varphi_{1}} \sum_{i=0}^{\infty} \varphi_{1}^{i} E_{t}\left(\hat{q}_{t+i}-\hat{a}_{t+i}\right)+\frac{\varphi_{0}\left(\varphi_{1}-\varphi_{2}\right)}{\varphi_{1}} \sum_{i=1}^{\infty} \varphi_{1}^{i} E_{t}\left(\hat{\pi}_{t+i}^{d}+\hat{\gamma}_{\tau, t+i}^{d}-\hat{\gamma}_{A, t+i}^{d}\right) .
\end{gathered}
$$

When $\gamma_{\tau}=\gamma_{A}$, the TOT follows

$$
\Delta \hat{\Psi}_{t}=\beta E_{t} \Delta \hat{\Psi}_{t+1}+\kappa_{\mu}\left(\hat{m} c_{t}^{d}-\hat{q}_{t}\right)
$$

Hence, in this simplified version of the TOT equation, the growth rate of the home TOT depends on the expected future growth rate of the home TOT and the real marginal costs differential in terms of the home currency unit. Eq.(5) implies that the TOT growth rate further relies on higher order leads of expectations of the future TOTs, the future real exchange rates, the future inflation differentials, and the future consumption differentials, respectively.

\footnotetext{
${ }^{13}$ This is the exactly same representation of the inflation differential dynamics as in Benigno (2004).
} 


\subsection{Symmetric two-country equilibrium}

In summary, the symmetric equilibrium of this two-country model is characterized by the following eight equations. Jointly with the home risk premium, the log-linear approximation of the home UIP is

$$
E_{t} \hat{s}_{t+1}-\hat{s}_{t}=\left(1+\hat{i}_{t}\right)^{d}+\psi(1-\kappa) \tilde{b}_{t}-E_{t} \hat{\gamma}_{\tau, t+1}^{d},
$$

where $\left(1+\hat{i}_{t}\right)^{d} \equiv\left(1+\hat{i}_{h, t}\right)-\left(1+\hat{i}_{f, t}^{*}\right)$ is the two country interest rate differential. Taking a difference between two countries' Euler equations and using the home UIP characterizes the forward-looking dynamics of the consumption differential $\hat{c}_{t}^{d}+\hat{a}_{t}$ as a function of the real exchange rate $\hat{q}_{t}$ and the net foreign asset position $\tilde{b}_{t}$ :

$$
\hat{c}_{t}^{d}-\hat{q}_{t}+\hat{a}_{t}-\psi(1-\kappa) \tilde{b}_{t}=E_{t}\left(\hat{c}_{t+1}^{d}-\hat{q}_{t+1}+\hat{a}_{t+1}\right) .
$$

The home and foreign good market clearing conditions determine the labor supply differential $\hat{N}_{t}^{d}$ as a static function of the terms of trade $\hat{\Psi}_{t}$, the productivity differential $\hat{a}_{t}$, and the price dispersion differential $\hat{\omega}_{t}^{d} \equiv \hat{\omega}_{h, t}-\hat{\omega}_{f, t}+\hat{\omega}_{h, t}^{*}-\hat{\omega}_{f, t}^{*}=\ln \Omega_{h, t} / \Omega_{f, t}+\ln \Omega_{h, t}^{*} / \Omega_{f, t}^{*}$ :

$$
\hat{N}_{t}^{d}+2 \zeta \hat{\Psi}_{t}+2 \hat{a}_{t}=\hat{\omega}_{t}^{d} .
$$

The transition of the price dispersion differential $\hat{\omega}^{d}$ is given as

$$
\hat{\omega}_{t}^{d}=-2 \varphi_{0}^{-1} \zeta\left\{1-\mu\left(\gamma_{\tau} / \gamma_{A}\right)^{\zeta}\right\} \Delta \hat{\Psi}_{t}+\mu\left(\gamma_{\tau} / \gamma_{A}\right)^{\zeta} \hat{\omega}_{t-1}^{d} .
$$

The home and foreign budget constraints characterize the equilibrium transition of the net foreign asset position $\tilde{b}_{t}$ :

$$
\tilde{b}_{t}=\beta^{-1} \tilde{b}_{t-1}+p c^{*}(1-\zeta) \hat{\Psi}_{t}-p c^{*}\left(\hat{c}_{t}^{d}+\hat{a}_{t}-\hat{q}_{t}\right),
$$

where $p c^{*}=p c / 4$. The home and foreign real marginal costs and the home and foreign intratemporal optimality conditions jointly determine the real marginal cost differential as a static function of terms of trade $\hat{\Psi}_{t}$, consumption differential $\hat{c}_{t}^{d}$, and labor supply differential $\hat{N}_{t}^{d}$ :

$$
\hat{m} c_{t}^{d}=-\hat{\Psi}_{t}+\hat{c}_{t}^{d}+\eta \hat{N}_{t}^{d}
$$

The home and foreign Taylor rules give the interest rate differential $\left(1+\hat{i}_{t}\right)^{d}$

$$
\left(1+\hat{i}_{t}\right)^{d}=\rho_{i}\left(1+\hat{i}_{t-1}\right)^{d}+a_{\pi}\left(\hat{\pi}_{t}^{d}-\hat{\gamma}_{A, t}^{d}\right)+a_{y} \hat{N}_{t}^{d}+\epsilon_{i, t}^{d} .
$$

Using the definition of the real exchange rate characterizes the relation among the real and nominal currency returns and the inflation differential

$$
\Delta \hat{q}_{t+1}=\Delta \hat{s}_{t+1}-\hat{\pi}_{t+1}^{d}+\hat{\gamma}_{A, t+1}^{d} .
$$

Rearranging the GNKPC of the inflation differential, eq.(4), provides the following second order 
expectational difference equation of the inflation differential

$$
\begin{array}{r}
\varphi_{1} \varphi_{2}\left(1+\varphi_{0}\right) E_{t}\left(\hat{\pi}_{t+2}^{d}+\hat{\gamma}_{\tau, t+2}^{d}-\hat{\gamma}_{A, t+2}^{d}\right)-\left[\varphi_{1}+\varphi_{2}\left(1+\varphi_{0}\right)-\varphi_{0}\left(\varphi_{1}-\varphi_{2}\right)(\zeta-1)\right] E_{t}\left(\hat{\pi}_{t+1}^{d}+\hat{\gamma}_{\tau, t+1}^{d}-\hat{\gamma}_{A, t+1}^{d}\right) \\
+\hat{\pi}_{t}^{d}+\hat{\gamma}_{\tau, t}^{d}-\hat{\gamma}_{A, t}^{d}=\varphi_{0}\left(1-\varphi_{1}\right) \hat{q}_{t}-\varphi_{0}\left(1-\varphi_{1}\right) \varphi_{2} E_{t} \hat{q}_{t+1}+\varphi_{0}\left(\varphi_{1}-\varphi_{2}\right) \hat{a}_{t}-\varphi_{0}\left(\varphi_{1}-\varphi_{2}\right) E_{t} \hat{a}_{t+1} \\
+\varphi_{0}\left(\varphi_{1}-\varphi_{2}\right) E_{t} \Delta \hat{c}_{t+1}^{d} .
\end{array}
$$

Similarly, rearranging the TOT dynamics (5) implies the following second order expectational difference equation of the terms of trade growth

$$
\begin{array}{r}
\Delta \hat{\Psi}_{t}-\left[\varphi_{2}+\varphi_{1}\left(1+\varphi_{0}\right)\right] E_{t} \Delta \hat{\Psi}_{t+1}+\varphi_{2}\left(1+\varphi_{0}\right) \varphi_{1} E_{t} \Delta \hat{\Psi}_{t+2}=\varphi_{0}\left(1-\varphi_{2}\right)\left(\hat{m} c_{t}^{d}-\hat{a}_{t}\right) \\
-\varphi_{0}\left(1-\varphi_{2}\right) \varphi_{1} E_{t}\left(\hat{m} c_{t+1}^{d}-\hat{a}_{t+1}\right)-\varphi_{0}\left(1-\varphi_{1}\right)\left(\hat{q}_{t}-\hat{a}_{t}\right)+\varphi_{0}\left(1-\varphi_{1}\right) \varphi_{2} E_{t}\left(\hat{q}_{t+1}-\hat{a}_{t+1}\right)+\varphi_{0}\left(\varphi_{1}-\varphi_{2}\right) E_{t} \Delta \hat{c}_{t+1}^{d} \\
+\varphi_{0}\left(\varphi_{1}-\varphi_{2}\right) E_{t}\left(\hat{\pi}_{t+1}^{d}+\hat{\gamma}_{\tau, t+1}^{d}-\hat{\gamma}_{A, t+1}^{d}\right) .
\end{array}
$$

The linear rational expectations model of this paper consists of nine stochastic difference equations (6)-(15) and determines nine endogenous variables $\hat{c}_{t}^{d}, \hat{N}_{t}^{d}, \hat{\omega}_{t}^{d}, \hat{m} c_{t}^{d}, \hat{s}_{t}, \hat{q}_{t}, \hat{\Psi}_{t},\left(1+\hat{i}_{t}\right)^{d}$, and $\tilde{b}_{t}$, given the stochastic processes of three exogenous variables $\hat{\gamma}_{\tau, t}^{d}, \hat{a}_{t}$, and $\epsilon_{i, t}^{d}$, including eqs.(1), and (2). ${ }^{14}$

\section{Random-walk real exchange rates within a restricted model}

In this section, I show that a restricted version of the model is able to generate near randomwalk exchange rates with large volatilities in a rational expectations equilibrium. Because the full specification of the model does not have an analytical solution, I impose several restrictions on the parameter space of the model to derive an approximated analytical solution of the real exchange rate.

To begin with, the Euler equation (7) rewrites the GNKPC (14) as

$$
\begin{array}{r}
\varphi_{1} \varphi_{2}\left(1+\varphi_{0}\right) E_{t}\left(\hat{\pi}_{t+2}^{d}+\hat{\gamma}_{\tau, t+2}^{d}-\hat{\gamma}_{A, t+2}^{d}\right)-\left[\varphi_{1}+\varphi_{2}\left(1+\varphi_{0}\right)-\varphi_{0}\left(\varphi_{1}-\varphi_{2}\right)(\zeta-1)\right] E_{t}\left(\hat{\pi}_{t+1}^{d}+\hat{\gamma}_{\tau, t+1}^{d}-\hat{\gamma}_{A, t+1}^{d}\right) \\
+\hat{\pi}_{t}^{d}+\hat{\gamma}_{\tau, t}^{d}-\hat{\gamma}_{A, t}^{d}=\varphi_{0}\left(1-2 \varphi_{1}+\varphi_{2}\right) \hat{q}_{t}+\varphi_{0}\left(\varphi_{1}-2 \varphi_{2}+\varphi_{1} \varphi_{2}\right) E_{t} \hat{q}_{t+1}+2 \lambda \varphi_{0}\left(\varphi_{1}-\varphi_{2}\right) \hat{a}_{t} \\
-\varphi_{0}\left(\varphi_{1}-\varphi_{2}\right) \phi(1-\kappa) \tilde{b}_{t} . \quad(16)
\end{array}
$$

Notice that the coefficients on $\hat{q}_{t}$ and $E_{t} \hat{q}_{t+1}$ are quite small numbers in absolute values. ${ }^{15}$ This means that the inflation differential is inelastic with real exchange rate developments. Because the steady state nominal discount factor $\kappa=\beta / \gamma_{\tau}$ is close to 1 and $\psi$ is conventionally calibrated to a very small positive number, the term $\psi(1-\kappa) \tilde{b}_{t}$ is negligible in the following approximated analytical solution of $\hat{q}_{t}$. The GNKPC then implies that the inflation differential $\Delta \ln P_{t}^{d} \equiv \hat{\pi}_{t}^{d}+\hat{\gamma}_{\tau, t}^{d}-\hat{\gamma}_{A, t}^{d}$ is approximately given as the present discounted values of expected future productivity differentials.

\footnotetext{
${ }^{14}$ Notice that $\hat{\gamma}_{A, t}^{d}=\hat{a}_{t}-\hat{a}_{t-1}$.

${ }^{15}$ Under the benchmark calibration discussed below, the calibrated coefficients on $\hat{q}_{t}$ and $E_{t} \hat{q}_{t+1}$ are 0.0024 and -0.0030, while those on $\hat{\pi}_{t}^{d}+\hat{\gamma}_{\tau, t}^{d}-\hat{\gamma}_{A, t}^{d}, E_{t}\left(\hat{\pi}_{t+1}^{d}+\hat{\gamma}_{\tau, t+1}^{d}-\hat{\gamma}_{A, t+1}^{d}\right)$, and $E_{t}\left(\hat{\pi}_{t+2}^{d}+\hat{\gamma}_{\tau, t+2}^{d}-\hat{\gamma}_{A, t+2}^{d}\right)$ are 1.000, -1.935 , and 0.927 , respectively. Indeed, if trend inflation is not allowed, the calibrated coefficients on $\hat{q}_{t}$ and $E_{t} \hat{q}_{t+1}$ sharply increase in the absolute value to 0.052 and -0.041 , respectively.
} 
Taylor rule differential (12) and home UIP condition (6) jointly provides the RUIP condition:

$$
E_{t} \hat{q}_{t+1}=\hat{q}_{t}+a_{\pi} \Delta \ln P_{t}^{d}-E_{t} \Delta \ln P_{t+1}^{d}-a_{\pi} \hat{\gamma}_{\tau, t}^{d}+\rho_{i}\left(1+\hat{i}_{t-1}\right)^{d}+a_{y} \hat{N}_{t}^{d}+\psi(1-\kappa) \tilde{b}_{t}+\epsilon_{i, t}^{d} .
$$

If I assume no output gap response of the Taylor rule by $a_{y}=0$ and no interest rate smoothing by $\rho_{i}=0$, the above RUIP condition is further simplified as

$$
\hat{q}_{t}=E_{t} \hat{q}_{t+1}+a_{\pi} \hat{\gamma}_{\tau, t}^{d}-a_{\pi} \Delta \ln P_{t}^{d}+E_{t} \Delta \ln P_{t+1}^{d}-\epsilon_{i, t}^{d} .
$$

Because the current and expected inflation differentials $\Delta \ln P_{t}^{d}$ and $E_{t} \Delta \ln P_{t+1}^{d}$ depend on real exchange rate $q_{t}$ to a negligible degree, iterating the above expectational difference equation with respect to $\hat{q}_{t}$ forward toward an infinite future derives the following present value representation of the real exchange rate ${ }^{16}$

$$
\hat{q}_{t}=a_{\pi} \sum_{s=0}^{\infty} E_{t} \hat{\gamma}_{\tau, t+s}^{d}-\epsilon_{i, t}^{d}+f\left(\hat{a}_{t}\right) .
$$

where $f\left(\hat{a}_{t}\right)$ is a bounded stationary function of the productivity differential $\hat{a}_{t}$. The real currency return $\Delta \hat{q}_{t}$ then follows

$$
\Delta \hat{q}_{t}=\frac{a_{\pi}}{1-\rho_{\tau}} \Delta \hat{\gamma}_{\tau, t}^{d}-\Delta \epsilon_{i, t}^{d}+\Delta f\left(\hat{a}_{t}\right) .
$$

Observe now that at the limit of $\rho_{\tau} \rightarrow 1$, the first term of the RHS of the above equation dominates the real currency return because the second and third terms are stationary with finite variances: ${ }^{17}$

$$
\lim _{\rho_{\tau} \rightarrow 1} \Delta \hat{q}_{t}=\lim _{\rho_{\tau} \rightarrow 1} \frac{a_{\pi}}{1-\rho_{\tau}} \epsilon_{\tau, t}^{d}
$$

Therefore, given trend inflation with $\rho_{\tau} \rightarrow 1$, the real exchange rate follows a near random walk with an infinite volatility. The real exchange rate enters into a permanent process in which the first difference has no serial correlation and an extremely large volatility induced by a shock to the trend inflation differential.

\section{Assessing the model by calibration}

\subsection{Empirical moments}

\footnotetext{
${ }^{16}$ The present value representation below is a restricted case of the fundamental asset pricing equation in Engel and West (2005):$$
z_{t}=(1-b) \sum_{j=0}^{\infty} b^{j} E_{t}\left(\mathbf{a}_{1}^{\prime} \mathbf{x}_{1, t+i}\right)+b \sum_{j=0}^{\infty} b^{j} E_{t}\left(\mathbf{a}_{2}^{\prime} \mathbf{x}_{2, t+j}\right),
$$

where $z_{t}$ is an asset price, $b$ is is discount factor, $\mathbf{x}_{1, t}$ is a vector of observable economic fundamentals, $\mathbf{x}_{2, t}$ is a vector of unobservable economics fundamentals, $\mathbf{a}_{1}$, and $\mathbf{a}_{2}$ are the corresponding coefficient vectors, respectively. Observe that eq.(17) is obtained by imposing $\mathbf{a}_{1}=\mathbf{0}$ and $b \rightarrow 1$. In this case, as proved by Engel and West (2005), if an element of the unobserved economic fundamentals $\hat{\gamma}_{\tau, t}^{d}$ is $\mathrm{I}(1)$, the real exchange rate converges to a random walk with an infinite variance of the real currency return.

${ }^{17}$ This proof borrows the argument found in the appendix of Engel and West (2005).
} 
In this paper, I assess the performance of the proposed model in terns of the empirical moments of the real and nominal exchange rates. The empirical moments this paper targets are summarized in the first row of Table 2. The first empirical moment is the sum of the autoregressive coefficients of the $\mathrm{AR}(5)$ process of the real exchange rate $\ln q_{t}$, denoted by $\alpha$. Steinsson (2008) conducts $\alpha$ from the augmented Dicky-Fuller regression with the fifth lags. He reports that the estimate of $\alpha$ is 0.954 with the $90 \%$ confidence interval between 0.879 and 1.000 for the U.S. trade-weighted real exchange rate. ${ }^{18}$

Steinsson (2008) and Burstein and Gopinath (2014) report a half-life measure, which is denoted by HL. The estimated ADF equation provides the impulse response functions (IRFs) of the real exchange rate with a unit reduced-form shock. The second empirical moment this paper targets, HL, is simply calculated as the maximum period before the IRF reaches 0.500 , i.e., $\mathrm{HL}=\mathrm{T}$ such that $\operatorname{IRF}(\mathrm{T}-1)>0.500$ and $\operatorname{IRF}(\mathrm{T}) \leq 0.500$. Burstein and Gopinath (2014) report HL for eight advanced countries. ${ }^{19}$ The cross-country average of the HL is 4.425 years with the minimum of 1.600 years for Switzerland and the maximum of 6.000 years for the United States.

The third empirical moment is the correlation coefficient between the real and nominal currency returns. It is well known that the real and nominal exchange rates co-move very much closely each other. In fact, Burstein and Gopinath (2014) show the correlation coefficients between the real and nominal currency returns over the eight advanced countries. The average of the correlation coefficient, denoted by Corr, is 0.932 with the minimum of 0.820 for Italy and the maximum of 0.990 for Japan. Notice that the tight co-movement between the real and nominal currency return implies that the exchange rate dynamics are almost disconnected with the inflation differential at least in the short run. Indeed, Burstein and Gopinath (2014) provide the ratio of the standard deviations of the real currency return to the nominal currency return, $\frac{\operatorname{Std}\left(\Delta \ln q_{t}\right)}{\operatorname{Std}\left(\Delta \ln S_{t}\right)}$, for the eight advanced economies. The cross-country average is 0.956 with the minimum of 0.870 for France and the maximum of 1.040 for the United Kingdom. The STD ratio close to one implies that the exchange rate is more volatile than the inflation differential. Figure 1 plots that the real currency return as the solid red line, the nominal currency return the dotted blue line, and the inflation differential the solid black line for the Japan and the United States between Q2:1985 and Q4:2014. Confirm that the real and nominal currency returns co-move almost one-to-one and the real and nominal currency returns are much more volatile than the inflation differential.

\subsection{Calibration}

The linear rational expectations (LRE) model derived in Section 2 has no analytical closedform solution. To capture the population properties, I conduct Monte Carlo simulations of the calibrated LRE model to generate synthetic time series samples of the real and nominal exchange rates and the inflation differential with 1,000 quarterly periods. I then calculate the theoretical moments using the synthetic samples to understand the model's implications for real and nominal exchange rate dynamics.

\footnotetext{
${ }^{18}$ The corresponding half-life, which is calculated through the conventional formula, $\log (0.5) / \log (\alpha)$, is equal to 3.649. This number is quite consistent with the conventional consensus about the real exchange rate's half-life of 3-5 years (Rogoff 1996).

${ }^{19}$ The eight countries includes Canada, France, Germany, Italy, Japan, Switzerland, the United Kingdom, and the United States.
} 
I follow the conventional calibrations of the structural parameters of the subjective discount factor and the Frisch labor supply elasticity by $\beta=0.990, \eta=2.000$, respectively. The Calvo probability of no price resetting is calibrated to $\mu=0.800$. The sensitivity parameters of the Taylor rule toward the inflation gap and the output gap are set to $a_{\pi}=1.500$ and $a_{y}=0.100$, respectively. The interest rate smoothing parameter is calibrated to $\rho_{i}=0.800$. Notice that Benigno (2004) shows that with the Calvo probability of no price resetting of 0.800 , the empirically plausible interest rate smoothing parameter around 0.800 fails to generate a sufficiently large persistence of the real exchange rate as in actual data.

A key parameter of the model is the long-run unconditional means of the trend inflation rate $\gamma_{\tau}$ and the labor productivity growth rate $\gamma_{A}$. Observe what actually matters for the equilibrium dynamics of the model is $\bar{\gamma} \equiv \gamma_{\tau} / \gamma_{A}$, i.e., the long-run unconditional mean of the trend inflation rate adjusted by the productivity growth rate (hereafter, long-run trend inflation). Notice that the transition of the price dispersion differential (9), the GNKPC (14), and the TOT dynamics (15) depend on $\bar{\gamma}$ through parameters $\varphi_{0}, \varphi_{1}$, and $\varphi_{2}$. As the benchmark calibration, I set $\bar{\gamma}=1.0084$, which is equivalent to $3.42 \%$ at annual rate.

The calibration of the price elasticity of demand $\zeta$ depends on $\bar{\gamma}$ crucially. To see this, recall that the price elasticity of demand is conventionally calibrated in the way that the model generates about $11-12 \%$ markup rate at the steady state. Under the GNKPC the steady-state markup rate is given by the inverse of the real marginal cost

$$
m c=\left(\frac{\zeta-1}{\zeta}\right)\left(\frac{1-\beta \mu \bar{\gamma}^{\zeta-1}}{1-\beta \mu \bar{\gamma}^{\zeta-2}}\right)\left(\frac{1-\mu}{1-\mu \bar{\gamma}^{\zeta-1}}\right)^{\frac{1}{1-\zeta}} .
$$

Notice that given $\bar{\gamma}=1$, the steady state markup rate returns to the conventional one, i.e., $\zeta /(\zeta-1)$. Under the benchmark calibration of $\beta, \mu$, and $\bar{\gamma}$ for the GNKPC above, I set $\zeta=22$ as the benchmark, which implies that the steady-state markup rate of $11.69 \%$.

Finally, the three exogenous impulses are calibrated as follows. The error correction speed of the cointegrated labor productivity process, $\lambda$, is set to 0.010 to reflect a quite slow cross-country productivity diffusion. The AR root of the trend inflation process is set to 0.990 to capture the slow mean-reverting property of the permanent component of the inflation differential as in data. Figure 2 plots that the quarterly sample of the inflation differential between Japan and the United States and the corresponding trend component extracted by the Hodrick and Prescott (HP) filter. The figure shows that there are substantial fluctuations in the trend component of the two-country inflation differential over the sample period. The trend component indeed moves very slowly around zero. ${ }^{20}$ The standard deviations of the productivity differential shock, the trend inflation differential shock, and the monetary policy differential shock are calibrated to $\sigma_{A}=0.010, \sigma_{\tau}=0.002$, and $\sigma_{i}=0.005$, respectively. The three shocks follow i.i.d. normal distributions with the zero means. Table 1 summarizes the benchmark calibration.

The above calibration guarantees the equilibrium of the LRE model to be determinant. I solve the unique equilibrium of the LRE model and derive the state-space representation using the

\footnotetext{
${ }^{20}$ The figure plots the demeaned time series of both the inflation differential and the HP trend component because the model with the symmetric two-countries has no implication of the unconditional mean.
} 
QZ algorithm by Sims for Monte Carlo simulations.

\subsection{Results of the benchmark model}

The second row of Table 2, which is labelled "Benchmark", reports the theoretical moments simulated with the benchmark model. Notice that the benchmark model fits to all of the targeted empirical moments fairly well. The benchmark model implies a quite large AR root of the real exchange rate: the sum of the AR (5) coefficients, $\alpha$, is simulated to 0.992 . In fact, this number is consistent with the empirical counterpart of 0.954 and surely within the $90 \%$ coverage of the cross-country sample. The benchmark model, hence, can generate a very high persistence of the real exchange rate as observed in actual data. Furthermore, the benchmark model yields a large half-life measure HL of 4.250 years, which mimics the empirical counterpart of 4.425 years very closely. This high value of the half-life measure stems from the fact that the benchmark model generates a strong hump-shaped impulse response of the real exchange rate. Figure 3 plots the simulated IRF of the real exchange rate calculated in the same way as in Steinsson (2008). The IRF peaks out after a year and monotonically but slowly declines toward zero over time. This hump-shaped pattern of the IRF of the real exchange rate is emphasized in the literature of the real exchange rate including Eichenbaum and Evans (1995), Cheung and Lai (2000), Steinsson (2008), Iversen and Sönderstörm (2014), and Burstein and Gopinath (2014). The benchmark model, therefore, is endowed with a strong propagation mechanism of the real exchange rate.

A natural question then is: which structural shock generates such a high persistence of the real exchange rate with the hump-shaped impulse response? To answer this question, I calculate the IRFs of the real exchange rate to the three structural shocks, productivity shock $\epsilon_{A, t}^{d}$, trend inflation shock $\epsilon_{\tau, t}^{d}$, and monetary policy disturbance $\epsilon_{i, t}^{d}$, from the state space representation of the benchmark model. The left window of Figure 4 plots the IRF of the real exchange rate to the one standard deviation shock to the productivity differential; the center window to the trend inflation shock; and the right window to the monetary policy shock, respectively. Confirm that the IRF to the trend inflation shock dominates those to the other two shocks in the absolute size. This means that even the calibrated size of the trend inflation shock is smaller than those of the other two shocks, the benchmark model amplifies and propagates the trend inflation shock greatly toward the real exchange rate. Observe also that only the IRF to the trend inflation shock is hump-shaped. It is, therefore, the trend inflation shock that generates the hump-shaped IRF of the real exchange rate as shown in Figure 3.

To capture an economic intuition behind this hump-shaped response of the real exchange rate to the trend inflation shock, it is convenient to solve the RUIP forward:

$$
\hat{q}_{t}=\sum_{j=0}^{\infty} E_{t} \Delta \ln P_{t+1+j}-\sum_{j=1}^{\infty} E_{t}\left(1+\hat{i}_{t+j}\right)^{d}+\lim _{j \rightarrow \infty} E_{t} \hat{q}_{t+j} .
$$

Notice that the last limiting term on the RHS will converge toward zero. Hence, the real exchange rate response depends positively on the difference between the expected present values of the future inflation rates and that of the future nominal interest rates. Figure 5 plots the IRFs of the nominal interest rate and the inflation rate to the trend inflation shock as the sold blue and red lines, respectively. Observe, on the one hand, that the IRF of the nominal interest rate is very persistent 
with a hump shape. This stems from the Taylor rule with the interest rate smoothing as well as the persistent adjustment of the inflation rate. On the other hand, while the inflation rate response is greater in the absolute value than the nominal interest rate response up to a year, the latter response gradually overcomes the former response after a year. The expected present values of the future nominal interest rates, hence, dominates that of the future inflation rates. This is the primary reason why the real exchange rate responds negatively to the trend inflation shock at the impact. Over periods of time the hump-shaped response of the nominal interest rate is reflected in the hump-shaped response of the real exchange rate though the above present value calculation.

\subsection{Into the Mussa puzzle}

The benchmark model also replicates successfully the two influential observations established by Mussa (1986) on the joint behavior of real and nominal exchange rates within the fixed and flexible exchange rate regimes before and after the breakdown of the Bretton Woods (BW) international monetary system. First, in the post BW period, the real exchange rates of the advanced economies almost perfectly co-move with the nominal exchange rates. Second, the short-run volatilities of the real exchange rates are much smaller under the BW period than those in the post BW period. Because it is hard for neoclassical real models with flexible prices to reconcile, these observations are well known as the Mussa puzzle. In a small open economy New Keynesian model, Monachelli (2004) shows that the price stickiness accompanied by incomplete pass though resolves the Mussa puzzle plausibly. Because of inheriting theoretical properties of Monacelli's (2004) model, the trend inflation model of this paper also passes this stringent reality check. ${ }^{21}$

The benchmark model, indeed, implies a high positive correlation coefficient between the real and nominal currency returns. The simulated correlation coefficient of 0.965 is also close to the empirical counterpart of 0.932 . The benchmark model successfully replicates a high volatility of the real exchange rate relative to the inflation differential as in actual data: the STD ratio of the real to nominal currency returns is 0.965 . This simulated value almost perfectly matches the empirical counterpart of 0.956 . Figure 6 plots the simulated synthetic time series of the real currency return as the solid red line, the nominal currency return the dotted blue line, and the inflation differential the solid black line. Observe that the real and nominal currency returns co-move almost perfectly. This result means that by construction the fluctuation in the inflation differential is very flat with a much smaller volatility than the volatilities of the real and nominal currency returns. The simulated relative volatilities of the real and nominal currency returns to the inflation differential in fact match the empirical counterparts.

To simulate synthetic time series in the BW period, I assume a managed exchange rate regime following Benigno (2004) in which the monetary authority in the foreign country adopts the Taylor rule including the nominal currency return

$$
\left(1+i_{f, t}^{*}\right)=\left(1+i^{*}\right)^{1-\rho_{i}}\left(1+i_{f, t-1}^{*}\right)^{\rho_{i}}\left(\frac{\gamma_{\pi, t}^{*}}{\gamma_{\tau, t}^{*}}\right)^{a_{\pi}}\left(y_{t}^{*}\right)^{a_{y}}\left(\frac{S_{t}}{S_{t-1}}\right)^{-\frac{\varphi}{1-\varphi}} \exp \left(\epsilon_{i, t}^{*}\right) .
$$

\footnotetext{
${ }^{21}$ Monacelli (2004), however, does not touch upon the persistence puzzle on which the recent literature of the real exchange rate puts strong emphasis.
} 
Parameter $\varphi \in[0,1)$ captures the degree of the managed exchange rate regime: the larger $\varphi$, the more stringent the managed regime is. If $\varphi=0$, the model returns to the benchmark specification with the flexible exchange rate. If $\varphi \rightarrow 1$, the model is subject to a strict fixed nominal exchange rate regime with $S_{t}=1$ for all $t$. If $\varphi \in(0,1)$, the model is characterized by a managed exchange rate regime. To calibrate parameter $\varphi$, I follow Monachelli (2004) and set $\varphi=0.760$. For a robustness check, I also simulate the model under a smaller calibration of $\varphi=0.500$.

Table 3 reports the simulated standard deviations of the real currency return and the inflation differential in the benchmark model and the managed exchange rate regime models. The first column corresponds to the benchmark model with $\varphi=0.000$. Observe that under the flexible exchange rate regime the real currency return is much more volatile than the inflation differential. The second column of the table corresponds to the managed exchange rate model with a smaller degree of the the sensitivity of the foreign country's Taylor rule to the nominal currency return $\varphi=0.500$. Notice that in this calibration the volatility of the real currency return is greatly weakened: the standard deviation of the real currency return of the benchmark model is almost seven times larger than that under the managed exchange rate model. Notice that on the other hand the volatility of the inflation differential is not changed much between the two exchange rate regimes: the standard deviation under the benchmark model is $1.803 \%$, while that under the managed exchange rate regime is $1.134 \%$. The alternative calibration for a more stringent managed exchange rate regime with $\varphi=0.760$ yields the same inference that the volatility of the real currency return jumps up sharply from the managed regime to the flexible regime, while there is no sharply change in the volatility in the inflation differential.

Figure 9 graphically verifies these successful properties of the model toward the Mussa puzzle. The figure plots the simulated time series of the real currency return as the dashed blue line and the simulated inflation rate differential as the solid black line under the calibration of $\varphi=0.500$. The two time series in the first 200 sample periods are simulated from the managed exchange rate model, while those in the second 200 sample periods from the benchmark model. On the one hand, the volatility of the real currency return rises sharply from the managed regime to the flexible regime. On the other hand, the volatility of the inflation differential stays to the almost same degree. ${ }^{22}$

In sum, the model of this paper replicates the observed structural change in the dynamics of the real exchange rate before and after the BW periods quite plausibly. As Monachelli (2004) infers, a regime change in the monetary policy rule should be the primary reason behind the Mussa puzzle.

\subsection{Contributions of long-run trend inflation}

\footnotetext{
${ }^{22}$ This successful outcome of the model toward the Mussa puzzle is explained intuitively. For simplicity, consider the strict fixed exchange rate regime with $\varphi=1$. In this case, $S_{t}=1$ for all $t$ and the real currency return is perfectly determined by the inflation differential, $\hat{q}_{t}=\hat{q}_{t-1}-\Delta \ln P_{t}^{d}$. Substituting this equilibrium relationship into the GNKPC of the inflation differential (16) provides the equilibrium dynamics of the real exchange rate. The equilibrium dynamics of the real exchange rate under the fixed exchange rate regime, thus, is completely governed by the relative price dynamics characterized by the GNKPC, rather than the asset price dynamics represented by the RUIP under the flexible exchange rate regime as in the benchmark model. This difference is the main reason why the volatility of the real exchange rate is smaller under the fixed exchange rate regime than that in the flexible one. The same intuition is applicable to the managed exchange rate model depending on the size of $\varphi$.
} 
The most crucial parameter of the benchmark model to generate successful outcomes on the exchange rate dynamics is the long-run trend inflation $\bar{\gamma}$. Recall that under $\bar{\gamma}=1$ the transition of the price dispersion differential (9), the GNKPC (14), and the TOT dynamics (15) are degenerated to the corresponding standard specifications in the conventional two-country NK model as in Benigno (2004). To clarify the contribution the long-run trend inflation $\bar{\gamma}$ makes to our understanding of the exchange rate dynamics more sharply, I simulate the model under no long-run trend inflation, $\bar{\gamma}=1$.

The third row of Table 2, which is labelled "No LR Trend Inflation", reports the simulated moments of the restricted model. First, the sum of $\operatorname{AR}(5)$ coefficient, $\alpha$, decreases sharply to 0.793 in the restricted model from the benchmark value of 0.992. Furthermore, the simulated half-life measure HL of 0.750 years uncovers the weak persistence of the real exchange rate within the restricted model. Therefore, without the long-run trend inflation the model fails to generate a sufficient degree of the persistence of the real exchange rate to match the empirical observation.

Moreover, the restricted model performs worse even in the other moments. The simulated correlation coefficient between the real and nominal currency returns, Corr, is 0.550, which is far below the minimum value of 0.820 among the Burstein and Gopinath's (2014) estimates. The simulated STD ratio of the real and nominal currency return sharply falls to 0.261 from 0.965 of the benchmark. This low value of the STD ratio implies that in the restricted model the volatility of the inflation differential is counterfactually large. To confirm this weak property of the restricted model, Figure 7 plots the simulated synthetic time series of the real currency return as the solid read line, the nominal currency return the dotted blue line, and the inflation differential the solid black line. Observe that the inflation differential has a quite large swing with a high volatility. The long-run trend inflation improves the model's empirical fit by damping down the inflation differential process.

\subsection{Roles of price elasticity of demand}

The most controversial calibration in the benchmark model might be about the price elasticity of demand $\zeta$. With a positive long-run trend inflation $\bar{\gamma}>1$, the price elasticity of demand $\zeta$ affects the transition of the price dispersion differential (9), the GNKPC (14), and the TOT dynamics (15). Contrary to the standard NK model with no long-run trend inflation, the price elasticity parameter plays a crucial role in the exchange rate dynamics in the benchmark model.

In the benchmark model, I set the parameter a quite large size of 22 because this value implies an empirically plausible markup rate of $11.690 \%$ through the markup equation (18). A careful investigation, however, reveals that the markup equation (18) is a quadratic U-shape equation as shown in Figure 8. Hence a conventional value of $\zeta$, say, around 10 also implies the markup rate of $11.780 \% .{ }^{23}$ This means that under a positive long-run trend inflation the conventional way of calibration of $\zeta$ by matching the theoretical markup rate to the estimated markup rate with actual data fails to pin down the value of $\zeta$. How can we find a plausible value of $\zeta$ within this two-country NK model with trend inflation?

\footnotetext{
${ }^{23}$ For example, using the post war U.S. data, Cogley and Sbordone (2014) estimate a single-equation GNKPC and reports that the median estimate of $\zeta$ is 9.8 with the $90 \%$ confidence interval between 7.4 and 12.1. Ascari and Sbordone (2014) set $\zeta$ to 10 in their discussion of their closed-economy NK model. To my best knowledge, there has been no estimate of $\zeta$ within an open-economy NK model with trend inflation.
} 
The fourth row of Table 2, which is labelled "Lower Price Elasticity", displays the implications on the exchange rate moments of the specification of the model with $\zeta=10$. The simulated sum of the AR(5) coefficients $\alpha$ of 0.964 is consistent with the empirical counterpart. The implied half-life measure HL of a year, however, is counterfactually low. This means that the model is absent from a strong propagation mechanism of the real exchange rate and cannot generate a hump-shaped impulse response as found in the empirical counterpart. The correlation between the real and nominal currency returns is simulated to 0.582 and the STD ratio of the two currency returns to 0.328. These numbers are far below the empirical counterparts. A lower price elasticity clearly worsens the fit of the model to the data properties of the exchange rates.

Therefore, the benchmark model with a larger value of $\zeta$ around 22 performs much better in terms of the exchange rate moments than the specification of the model with a conventional value of the price elasticity around 10. Developing a better estimation of the price elasticity of demand is beyond the scope of this paper. I leave this as an important future task of the literature.

\section{Conclusion}

In this paper I argue that allowing for trend inflation in an otherwise standard two-country NK model fundamentally changes exchange rate dynamics. A positive long-run trend inflation implies a more persistent but less volatile inflation differential with the GNKPCs of the two countries. At the same time, the GNKPCs weaken the linkage between the inflation differential and the real exchange rate. The RUIP condition jointly with the Taylor rules then generates a nearly permanent real exchange rate with a large volatility. Combined with the less volatile inflation differential, the real and nominal currency returns co-move almost perfectly in an equilibrium of the model.

Because the model of this paper is still absent from many other theoretical features that the recent literature of the international relative prices emphasize to approach exchange rate anomalies. For example, the benchmark specification has neither home-bias nor distributional margin. As a result, the benchmark model implies an almost one-to-one correspondence of the real exchange rate to the consumption differential even under incomplete international financial markets. Including these features into the benchmark model is an important future task to approach Backus and Smith's (1993) anomaly.

\section{References}

Ascari, G., Sbordone, A.M., 2014, The macroeconomics of trend inflation, Journal of Economic Literature 52, 679-739.

Backus, D.K., Smith, G.W., 1993, Consumption and real exchange rates in dynamic economies with non-traded goods, Journal of International Economics 35, 297 - 316.

Benigno, G., 2004, Real exchange rate persistence and monetary policy rules, Journal of Monetary Economics 51, 473 - 502. 
Betts, C., Devereux, M., 1996, The exchange rate in a model with pricing-to-market, European Economic Review 40, 1007 - 1021.

Burstein A., Gopinath, G., 2014, International prices and exchange rates, in Gopinath, G., Helpman, E., and Rogoff, K. eds., Handbook of International Economics, vol 4, 391 - 451, North Holland/Elsevier, London.

Chari, V.V., Kehoe, P.J., McGrattan, E.R., 2002, Can sticky price models generate volatile and persistent real exchange rates?, Review of Economic Studies 69, 533 - 563.

Cheung, Y.-W., and Lai, K.S., 2000, On the purchasing power parity puzzle. Journal of International Economics, 52, 321-330.

Cogley, T., Sbordone, A.M., 2008, Trend inflation, indexation, inflation persistence in the new Keynesian Phillips curve, American Economic Review 98, 2101 - 2126.

Eichenbaum, M., Evans, C.I., 1995, Some empirical evidence in the effects of shocks to monetary policy on exchange rates, Quarterly Journal of Economics 110, 975-1009.

Engel, C., 2014, Exchange rates and interest parity, in Gopinath, G., Helpman, E., and Rogoff, K. eds., Handbook of International Economics, vol 4, 453 - 522, North Holland/Elsevier, London.

Engel, C., West, K.D., 2005, Exchange rates and fundamentals, Journal of Political Economy 113, $485-517$.

Ireland, P., 2007, Changes in the Federal Reserve's inflation target: causes and consequences, Journal of Money, Credit, and Banking 39, 1851 - 1882.

Iversen, J. and Sönderstörm, U. 2014, The dynamic behavior of the real exchange rate in sticky price models, American Economic Review 104, 1072-1089.

Kano, T., 2016, Exchange rates and fundamentals: a general equilibrium exploration, Hitotsubashi Institute for Advanced Study Discussion Paper HIAS-E-19.

Nason, J.M., Rogers, J.H., 2008, Exchange rates and fundamentals: a generalization, Federal Researve Bank of Atlanta Working Paper.

Mussa, M., 1986, Nominal exchange rate regimes and the behavior of real exchange rates: evidence and implications, Carnegies-Rochester Conference Series on Public Policy 25, 117-214.

Monacelli, T, 2004, Into the Mussa puzzle: monetary policy regimes and the real exchange in a small open economy. Journal of International Economics 62, 191-217.

Steinsson, J., 2008, The dynamic behavior of the real exchange rate in sticky price models, American Economic Review 98, 519-533. 


\section{Table 1: Benchmark Calibration of Trend Inflation Model}

\begin{tabular}{llc}
\hline & \multicolumn{1}{c}{ Parameters } & Values \\
\hline \hline$\beta$ & Subjective Discount Factor & 0.990 \\
$\bar{\gamma}$ & Mean Adjusted Trend Inflation Rate & 0.0084 \\
$\eta$ & Labor Supply Elasticity & 2.000 \\
$\zeta$ & Price Elasticity of Final Goods Demand & 22.000 \\
$\mu$ & Calvo probability of No Price Resetting & 0.800 \\
$a_{\pi}$ & Taylor Rule Parameter on Inflation Gap & 1.500 \\
$a_{y}$ & Taylor Rule Parameter on Output Gap & 0.100 \\
$\rho_{i}$ & Interest Rate Smoothing Parameter & 0.800 \\
$\lambda$ & Error Correction Speed of Productivity Shock & 0.010 \\
$\rho_{\tau}$ & Trend Inflation Differential AR(1) Coef. & 0.990 \\
$\sigma_{A}$ & Productivity Differential Shock Std. & 0.010 \\
$\sigma_{\tau}$ & Trend Inflation Differential Shock Std. & 0.002 \\
$\sigma_{i}$ & Monetary Policy Shock Std. & 0.005
\end{tabular}

Note 1. Price elasticity of demand $\zeta$ is calibrated to match the steady state markup rate to $11.690 \%$. Note 2. Calibrated long-run adjusted trend inflation rate $\bar{\gamma}$ corresponds to to $3.420 \%$ at annual rate. 


\section{Table 2: Data and Simulated Moments of Exchange Rates}

\begin{tabular}{lcccc}
\hline \hline & $\alpha$ & HL & Corr & $\frac{\operatorname{Std}\left(\Delta \ln q_{t}\right)}{\operatorname{Std}\left(\Delta \ln S_{t}\right)}$ \\
\hline $\begin{array}{l}\text { Empirical } \\
90 \% \text { CI or }\{\text { min, } \max \}\end{array}$ & 0.954 & 4.425 & 0.932 & 0.956 \\
& {$[0.8791 .000]$} & $\{1.6006 .000\}$ & $\{0.8200 .990\}$ & $\{0.8701 .040\}$ \\
Benchmark & 0.992 & 4.250 & 0.965 & 0.965 \\
$\begin{array}{l}\text { No LR Trend Inflation } \\
(\bar{\gamma}=1)\end{array}$ & 0.792 & 0.750 & 0.550 & 0.261 \\
$\begin{array}{l}\text { Lower Price Elasticity } \\
(\zeta=10)\end{array}$ & 0.964 & 1.000 & 0.582 & 0.328 \\
\hline
\end{tabular}

Note 1: $\alpha$ is the sum of the AR coefficients in the AR(5) process of $\ln q_{t}$.

Nore 2. Half-life measure HL is the maximum period at which the impulse response function of the real exchange rate is greater than 0.5 . HL is measured in years.

Note 3. Corr represents the correlation coefficient between $\Delta \ln q_{t}$ and $\Delta \ln S_{t}$.

Note 4. $\frac{\operatorname{Std}\left(\Delta \ln q_{t}\right)}{\operatorname{Std}\left(\Delta \ln S_{t}\right)}$ represents the ratio of the standard deviations of $\Delta \ln q_{t}$ to $\Delta \ln S_{t}$.

Note 5: In the "Empirical" row, $\alpha$ comes from Steinsson's (2008) estimate using the U.S. trade weighted real exchange rate. The other statistics stem from Burstein and Gopinath (2014). Each of them exhibits the average of the point estimates over the eight advanced countries. 
Table 3: Simulated Volatilities Between Flexible and Managed Exchange Rate Regimes

\begin{tabular}{lccc}
\hline \hline & Benchmark & \multicolumn{2}{c}{ Managed } \\
& $\varphi=0.000$ & $\varphi=0.500$ & $\varphi=0.750$ \\
\hline $\operatorname{Std}\left(\Delta q_{t}\right) \%$ & 6.717 & 0.972 & 0.388 \\
$\operatorname{Std}\left(\Delta \ln P_{t}^{d}\right) \%$ & 1.803 & 1.134 & 0.637 \\
\hline
\end{tabular}




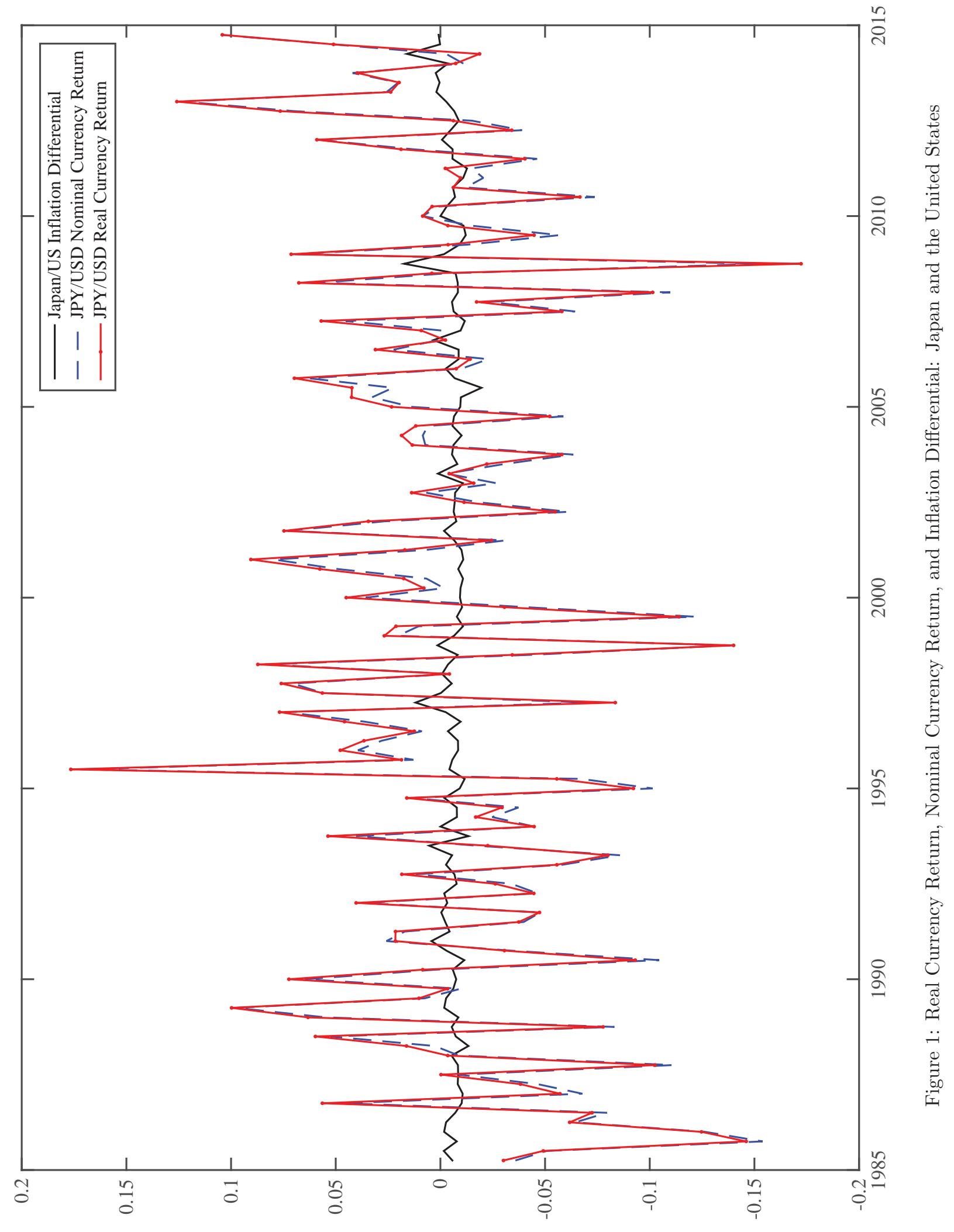




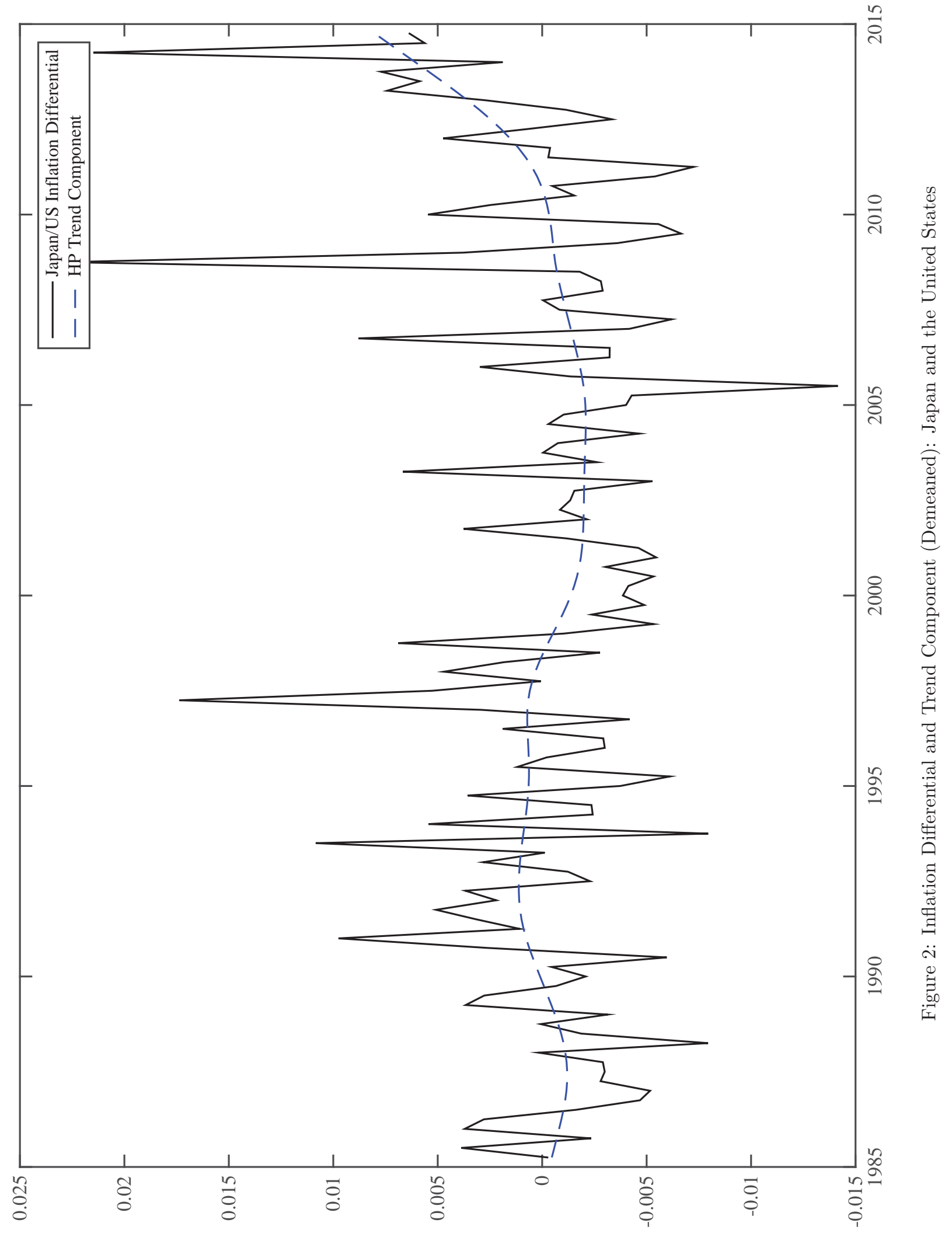




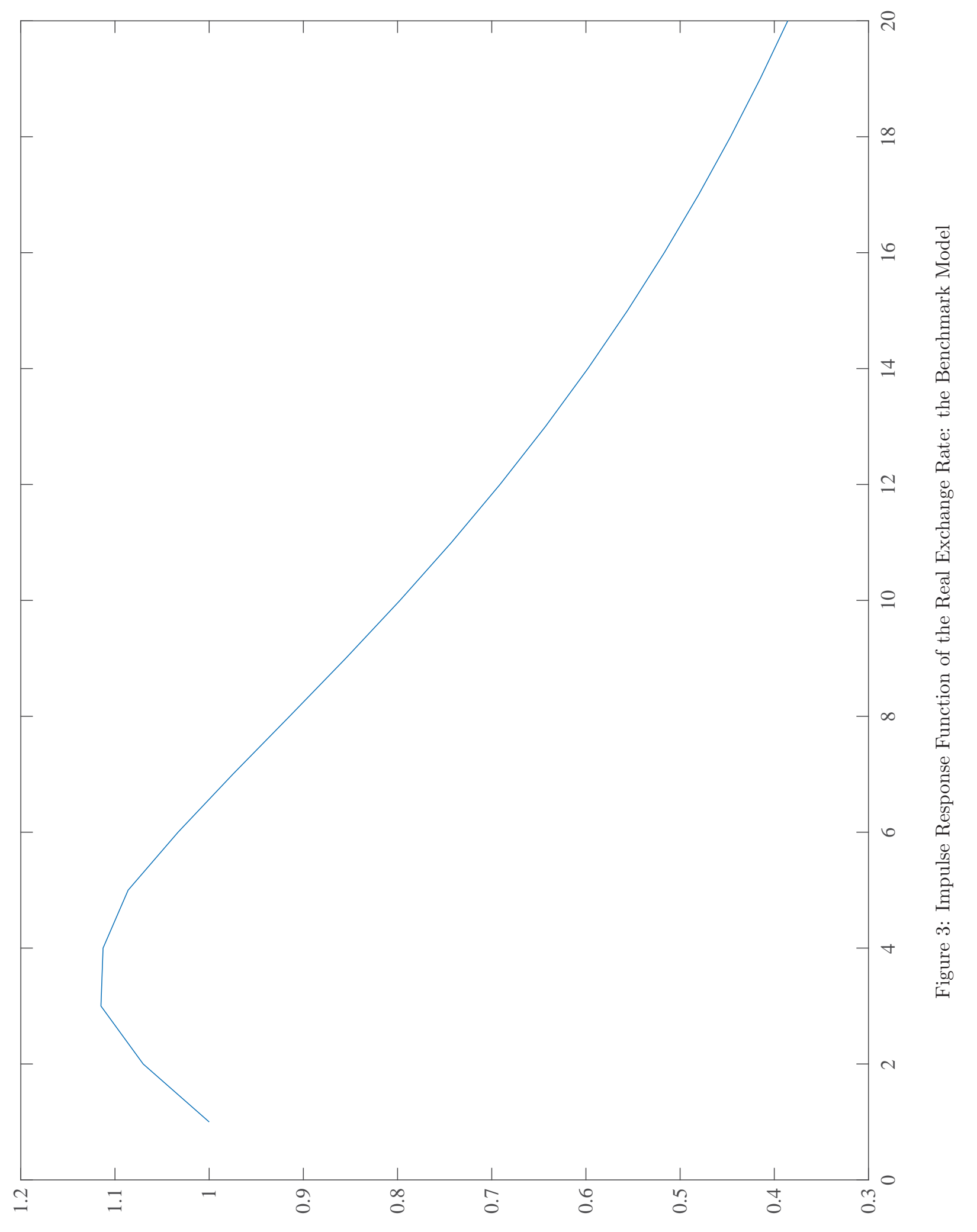



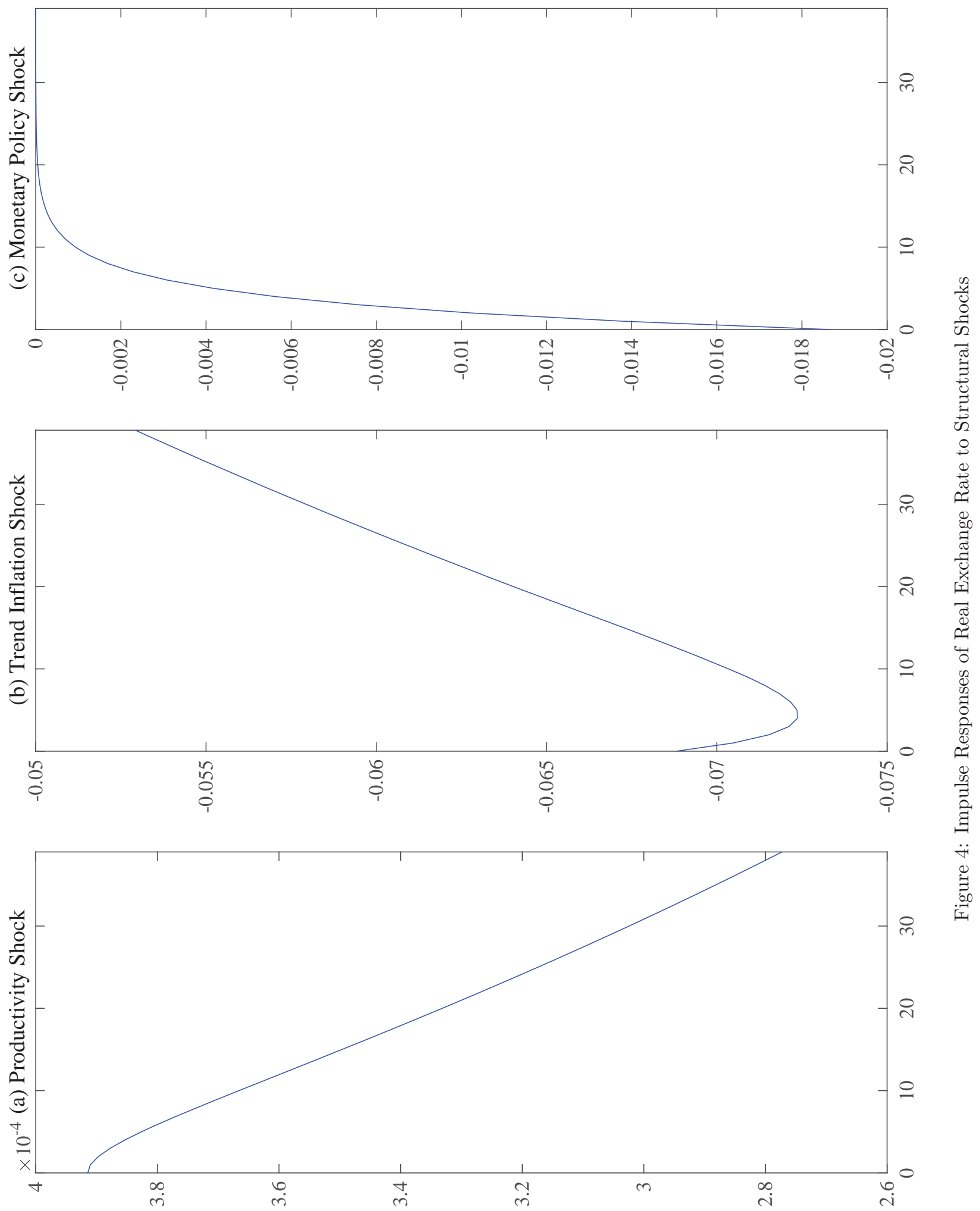


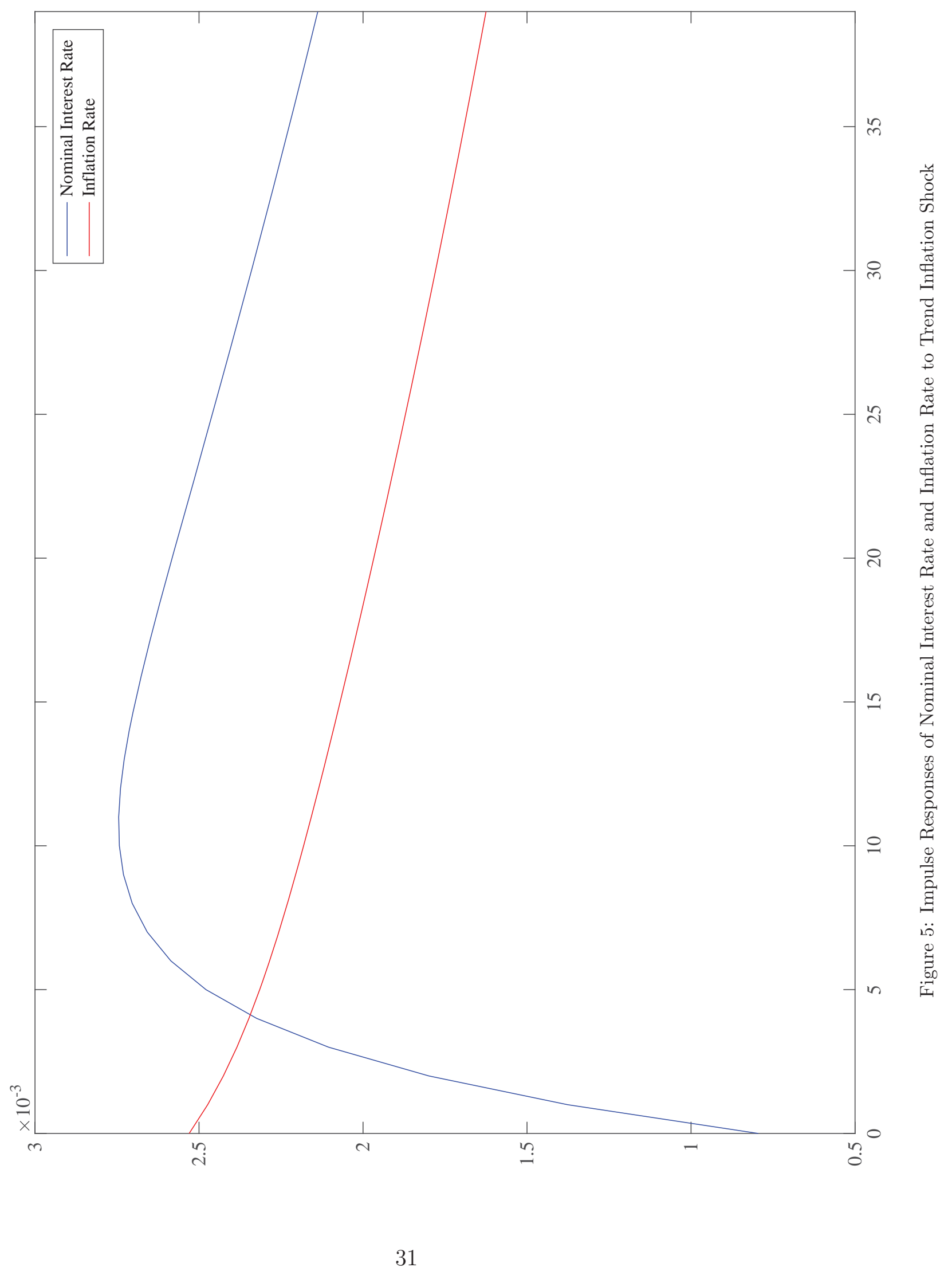




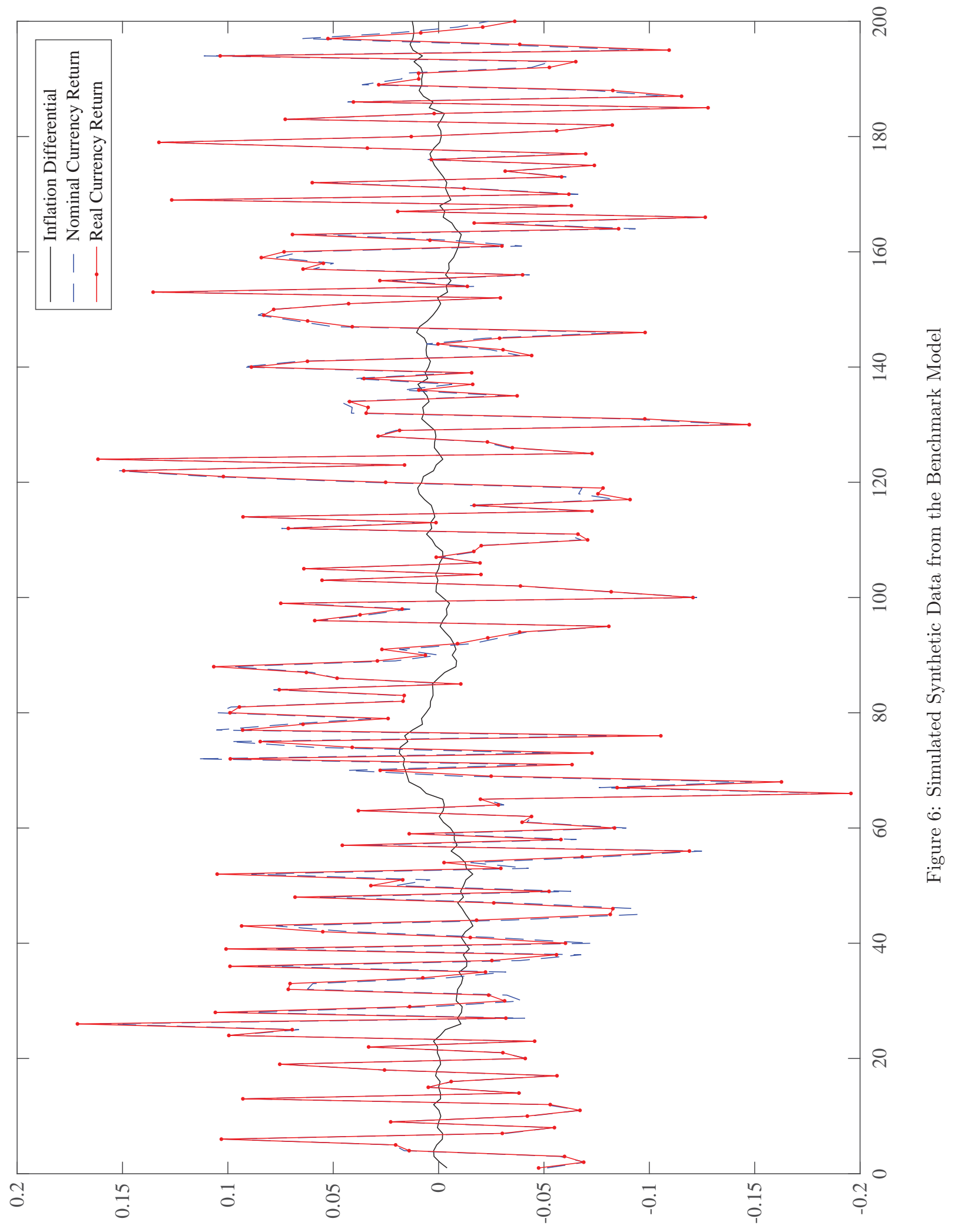




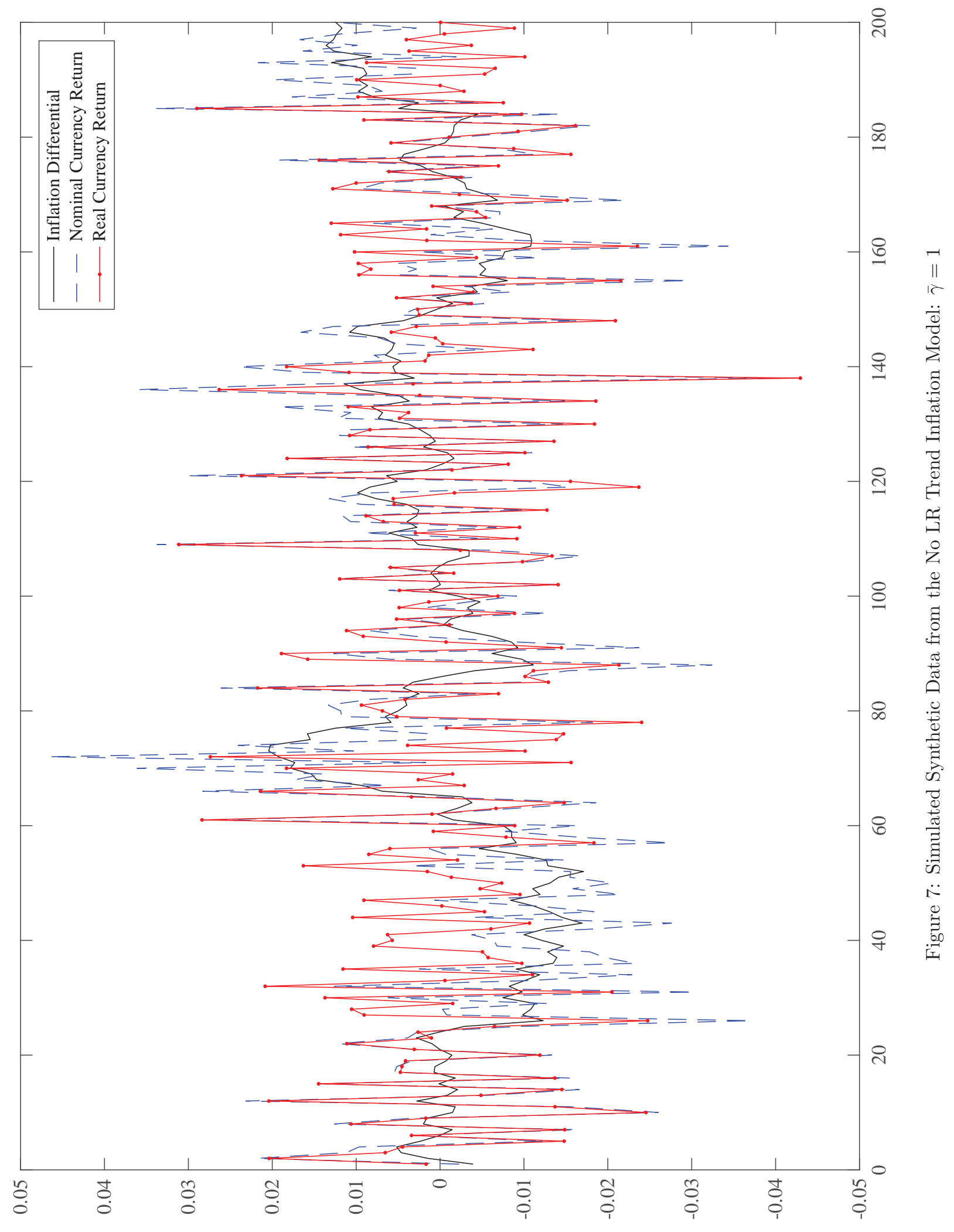




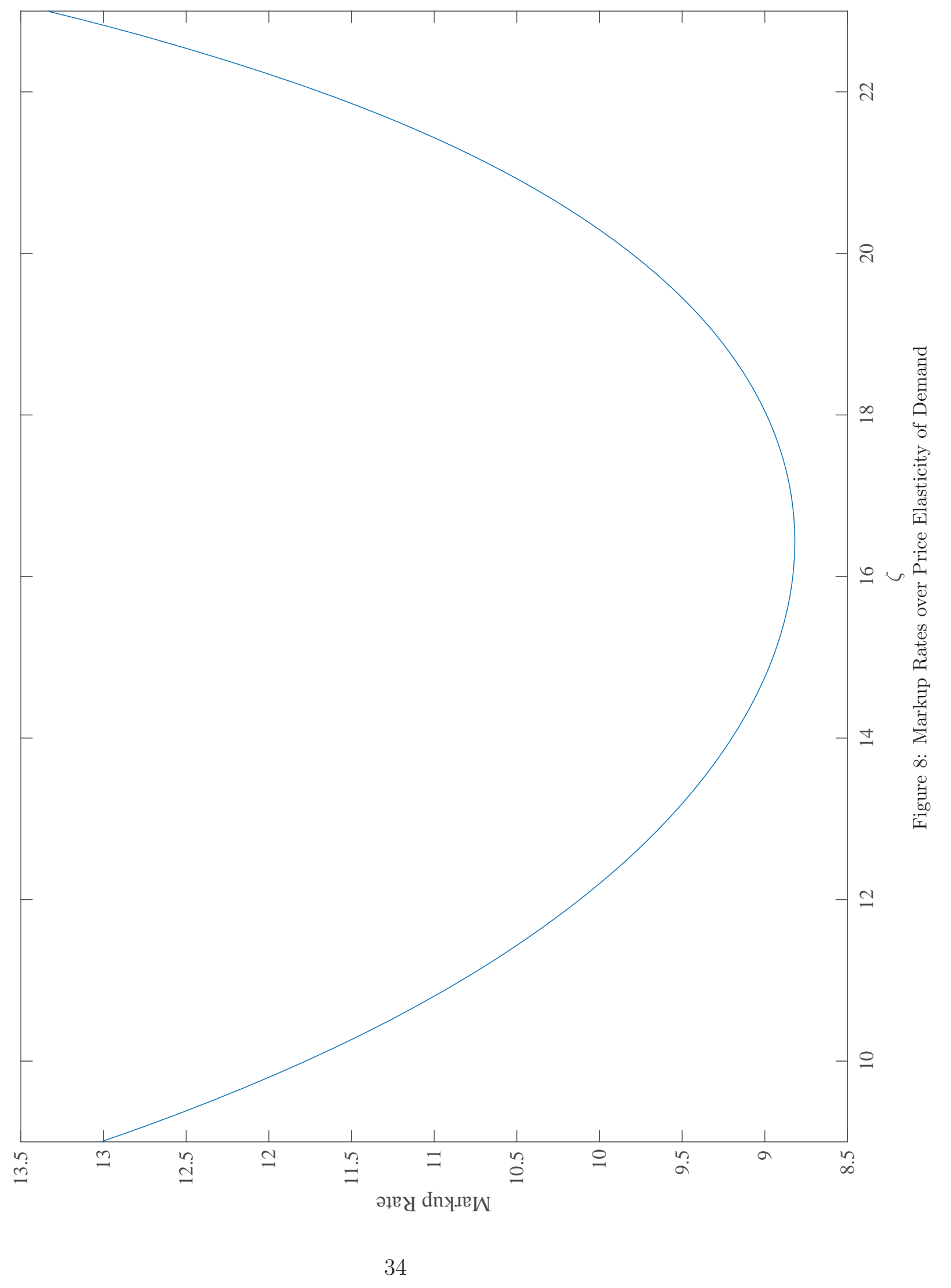




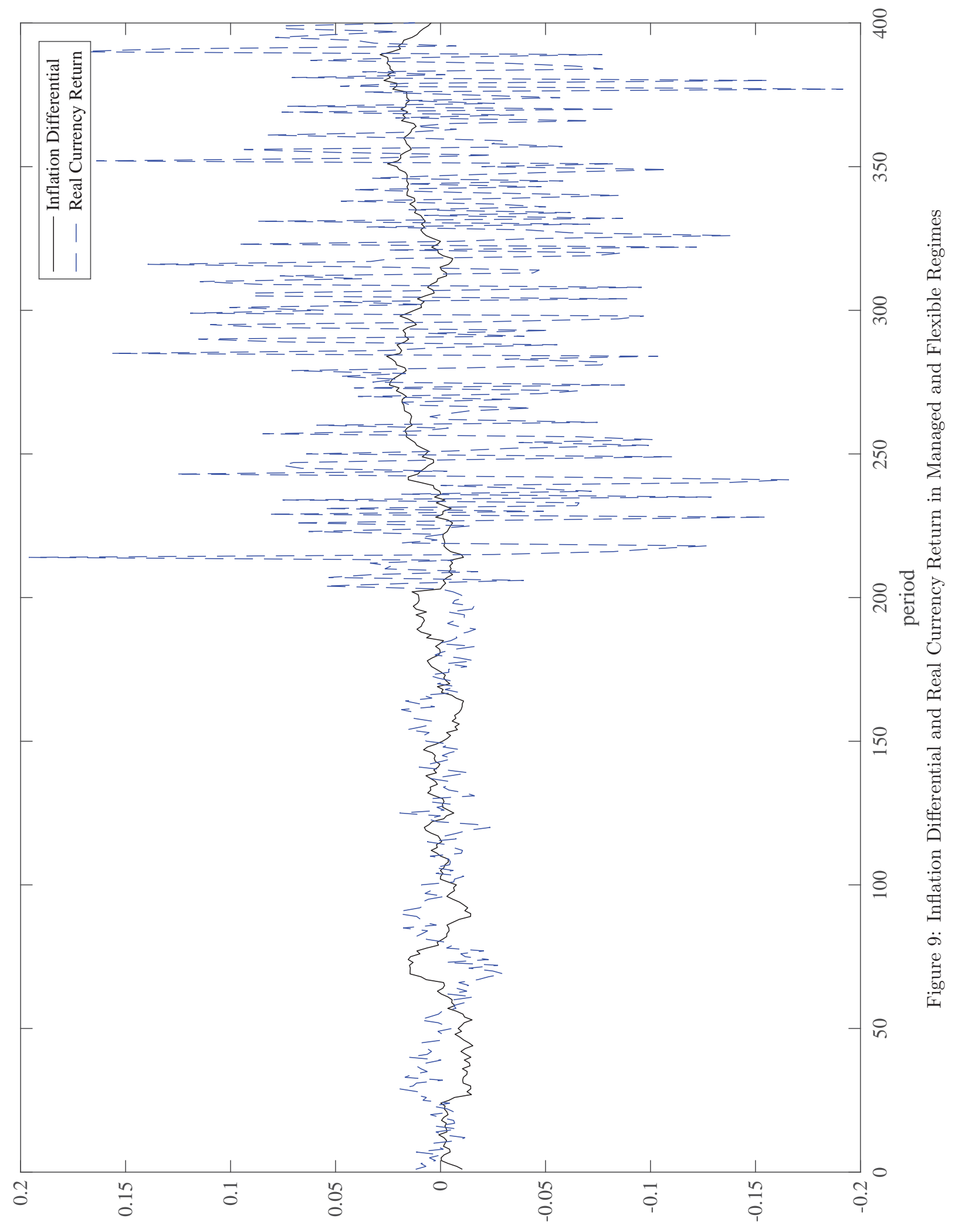

